\section{Pacific Northwest}

National Laboratory

Operated by Battelle for the

U.S. Department of Energy

\title{
EnergyWeb Screening Criteria Report
}

S.E. Widergren

R.T. Guttromson

M.C. Baechler

January 2003

Prepared for the

Office of Distributed Energy and Electric Reliability,

Transmission Reliability Program

Assistant Secretary for Energy Efficiency and Renewable Energy

U.S. Department of Energy

under Contract DE-AC06-76RL01830 


\title{
DISCLAIMER
}

This report was prepared as an account of work sponsored by an agency of the United States Government. Neither the United States Government nor any agency thereof, nor Battelle Memorial Institute, nor any of their employees, makes any warranty, express or implied, or assumes any legal liability or responsibility for the accuracy, completeness, or usefulness of any information, apparatus, product, or process disclosed, or represents that its use would not infringe privately owned rights. Reference herein to any specific commercial product, process, or service by trade name, trademark, manufacturer, or otherwise does not necessarily constitute or imply its endorsement, recommendation, or favoring by the United States Government or any agency thereof, or Battelle Memorial Institute. The views and opinions of authors expressed herein do not necessarily state or reflect those of the United States Government or any agency thereof.

\author{
PACIFIC NORTHWEST NATIONAL LABORATORY \\ operated by \\ BATTELLE \\ for the \\ UNITED STATES DEPARTMENT OF ENERGY \\ under Contract DE-AC06-76RL01830
}

Printed in the United States of America

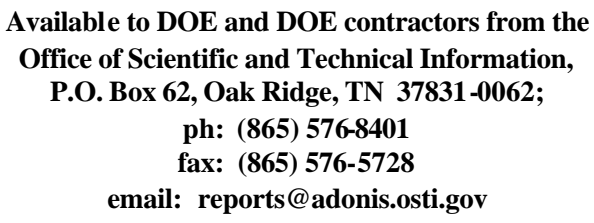

Available to the public from the National Technical Information Service, U.S. Department of Commerce, 5285 Port Royal Rd., Springfield, VA 22161 ph: (800) 553-6847 fax: $(703) 605-6900$

email: orders@ntis.fedworld.gov online ordering: http://www.ntis.gov/ordering.htm This document was printed on recycled paper. 


\title{
EnergyWeb Screening Criteria Report
}

\author{
S.E. Widergren \\ R.T. Guttromson \\ M.C. Baechler
}

January 2003

Prepared for

The U.S. Department of Energy

Office of Distributed Energy and Electric Reliability,

Transmission Reliability Program

Assistant Secretary for Energy Efficiency and Renewable Energy

under Contract DE-AC06-76RL01830

Pacific Northwest National Laboratory

Richland, Washington 99352 


\section{Summary}

This report describes a framework for evaluating distributed energy resource (DER) candidates to participate as an aggregated pool of controllable energy devices to meet local and system-wide needs of the power system. The framework includes a definition of system goals, the relevant material that characterizes a DER candidate, the rules for evaluating candidate participants, and a process that utilizes this information to produce a list of the most attractive candidates.

The work is sponsored by the Load as a Resource research area of CERTS (the Consortium for Electric Reliability Technology Solutions) whose vision is to "improve the performance of competitive electricity markets - while enhancing the reliability and security of the grid - through meaningful demand-side response to price or system conditions." Consistent with this vision, the Bonneville Power Administration (BPA) plans to construct a test-bed of aggregated DER to gain knowledge about the behavior of these resources, including their ability to meet system needs. Their ideas are embodied in a concept they call EnergyWeb. EnergyWeb recognizes the trends toward less expensive, more capable intelligent controls and sensors, the widespread access to communication, and the increasing deployment of distributed energy resources (DER), including small generation, storage, and controllable load. These trends, combined with the drive toward market-based systems to enhance energy utilization, motivate the electric power industry to imagine new modes of operation.

To manage the increasing number of DER integrated into the electric system, new organizations that aggregate these resources are beginning to appear. These "aggregators" will help form a competitive market in which single agencies may be replaced with multiple energy service providers from which to buy power and other services, thus giving consumers greater control of how they spend their energy dollars. By combining many DER, the aggregator is able to participate in the buying and selling of energy at the bulk power level, while delivering services to their retail clients. This idea allows smaller electricity producers and demand response systems to reduce the load seen from the head of a distribution feeder, helping to ease the energy market problems while obtaining compensation in return. In the near term, harnessing such resources may help support utility issues such as relieving capacity constraints on the distribution system or firming energy from unpredictable energy sources such as wind farms.

A demonstration of the EnergyWeb concept requires the aggregation of many resources. But what characteristics make a DER attractive to such a program? How can an aggregator value the contribution of a participating resource? The screening criteria described in this report provide a step toward addressing these questions by organizing an approach to evaluate potential resources. The Department of Energy, CERTS, and BPA plan to take further steps with EnergyWeb and Load as a Resource research to spur positive change that transforms today's system into an even more effective system ready to confront the energy issues of the future. 


\section{Acknowledgements}

The work described in this report was coordinated by the Consortium for Electric Reliability Technology Solutions and was funded by the Assistant Secretary for Energy Efficiency and Renewable Energy, Office of Distributed Energy and Electric Reliability, Transmission Reliability Program of the U.S. Department of Energy under Contract no. DE-AC06-76RL01830.

The authors also want to thank the following people who contributed to this document through interviews or critical review of aspects of this report:

- Bob Lahmann, Gordon Comegys, and Mike Raschio, Bonneville Power Administration, for their insight into regional issues in the transmission grid

- Sixth Dimension, represented by Bud Vos, for the requirements to integrate the communication and control of the distributed resources

- Brad Hodges, Dale McLean, and Dennis Quinn from Celerity Energy, for their input into the upgrades typically needed to properly integrate distributed energy resources (DER) into the electric system

- Marc Ledbetter, Jeff Dagle, Michael Kintner-Meyer, and Lawrence Schienbein from Pacific Northwest National Laboratory (PNNL) for their review and constructive feedback of the screening approach during its development. 


\section{Acronyms and Definitions}

Ancillary Services Services provided to control the power system in normal and emergency operation. Examples include balancing energy to follow load changes, energy reserves to be called upon in the event of a system outage, and voltage regulation.

BPA Bonneville Power Administration - federal agency that supplies transmission and coordinates hydrogenation in the Pacific Northwest

CARB California Air Resources Board - environmental regulatory body in the State of California concerned with the engine emissions

CCCT combined-cycle combustion turbine - generation derived from turbines driven by combustion gases, as well as from the steam produced from the waste heat of these gases

CEC California Energy Commission - California state energy policy and planning agency

CO carbon monoxide - emission from carbon-based fueled generators monitored for environmental impact

CT combustion turbine - natural gas based fueled generator characterized by turbines driven by hot gases produced during combustion

DER distributed energy resource - all varieties of generation, storage, and controllable load in the distributed (load serving, lower voltage) parts of the power system

DG distributed generation - generally $50 \mathrm{~kW}$ to $10 \mathrm{MW}$ generators installed to meet a local electric energy demand.

EIS Environmental Impact Statement - report describing the likely affect of installing new generation or upgrading an existing site.

EPA Environmental Protection Agency - federal agency whose mission is to safeguard human health and protect the natural environment

EPRI Electric Power Research Institute - a science and technology research consortium serving the energy industry

HC hydrocarbons - emission from carbon-based fueled generators monitored for environmental impact 
LTC load tap changing - terminology applied to power system transformers with controls that can be adjusted depending upon the load or voltage in their vicinity

NMHC non-methane hydrocarbons - emission from carbon-based fueled generators monitored for environmental impact

$\mathbf{N O}_{\mathbf{x}} \quad$ nitrogen oxides - emission from carbon-based fueled generators monitored for environmental impact

NREL National Renewable Energy Laboratory - Department of Energy national laboratory focused on renewable energy and energy efficiency research, located in Golden, Colorado

O\&M operations and maintenance - this generally refers to the costs associated with operating and maintaining a piece of equipment or a facility

PM particulate matter - measure of emitted particles from carbon-based fueled generators monitored for environmental impact

PNNL Pacific Northwest National Laboratory - Department of Energy national laboratory located in Richland, Washington

PV photovoltaic - electric energy production device that transforms sunlight into electric energy

SCR selective catalytic reduction - emissions device attached to the exhaust of carbon-based fueled generators to reduce emissions

SEPA State Environmental Policy Act - Washington state environmental policy intended to identify possible environmental impacts that may result from government decisions 


\section{Contents}

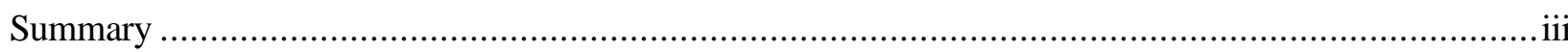

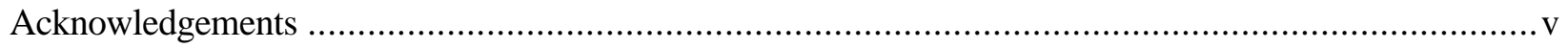

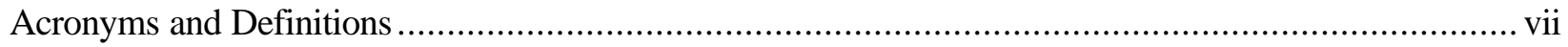

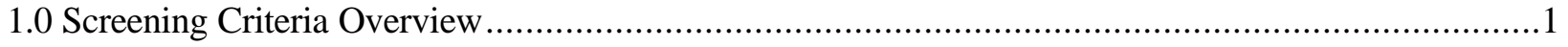

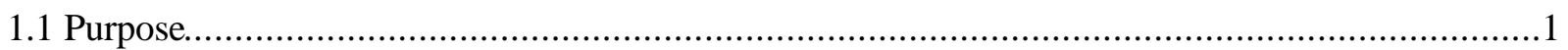

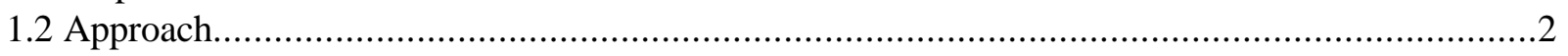

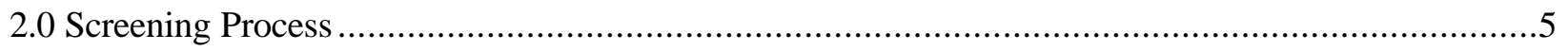

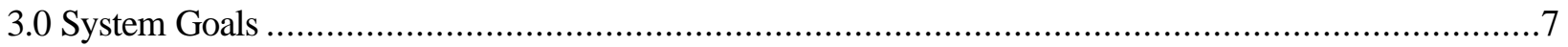

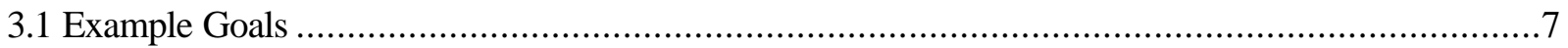

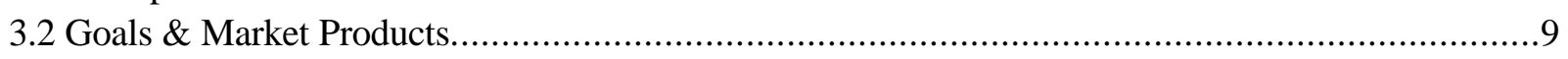

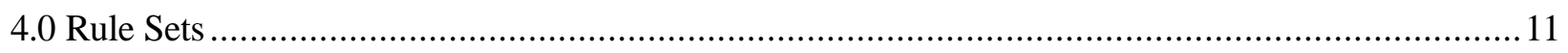

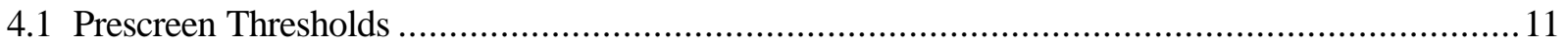

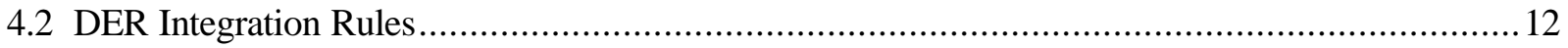

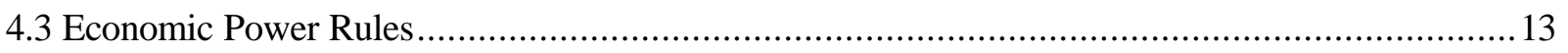

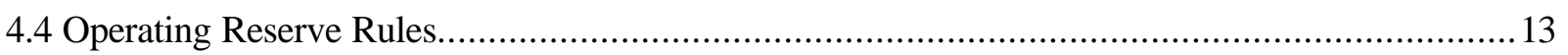

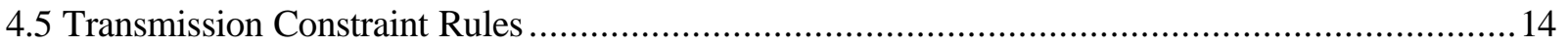

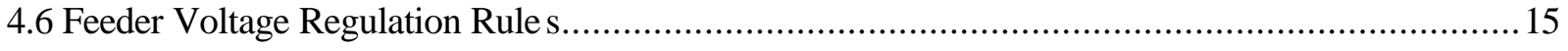

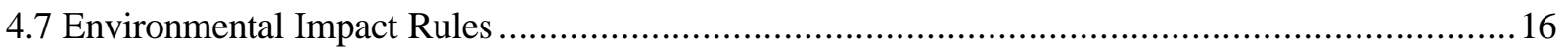

4.7.1 Power Plant Siting and Review ......................................................................... 17

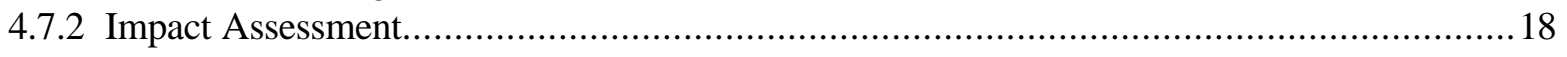

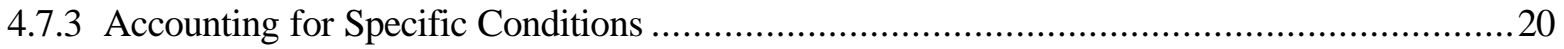

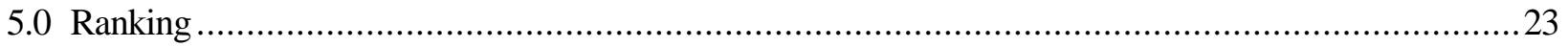

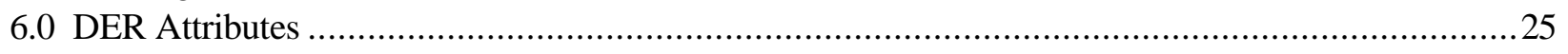

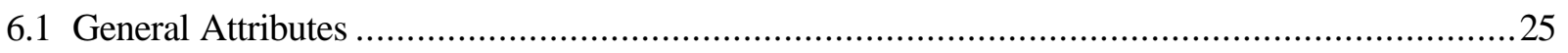

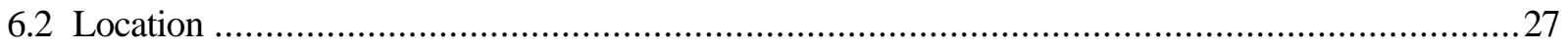

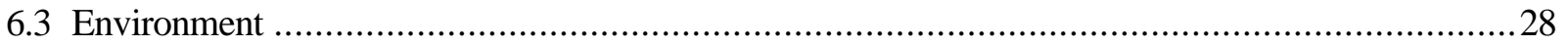

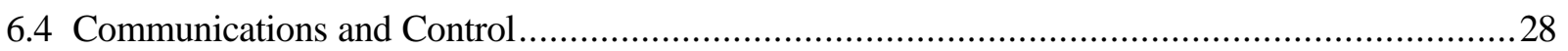

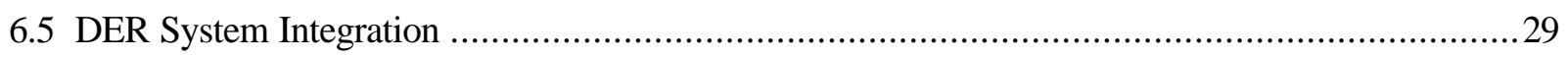

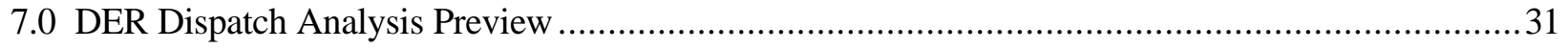

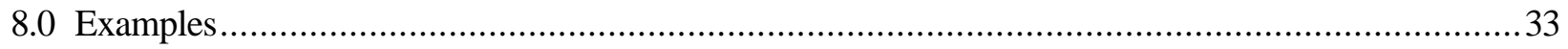

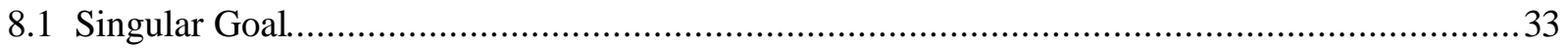

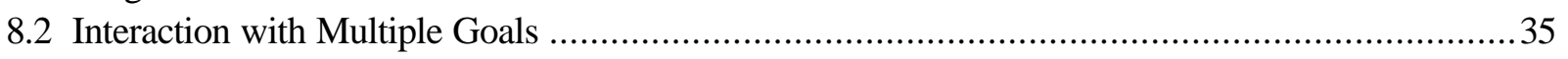

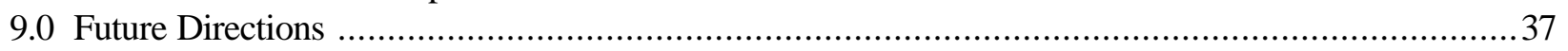

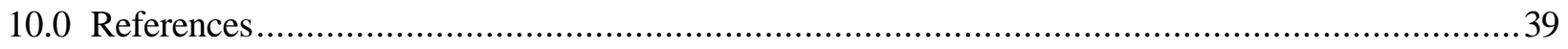

Appendix A: Practical Considerations for DER Screening .......................................................

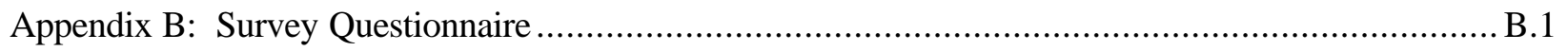




\section{Figures}

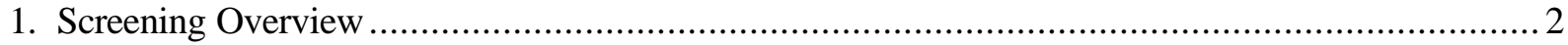

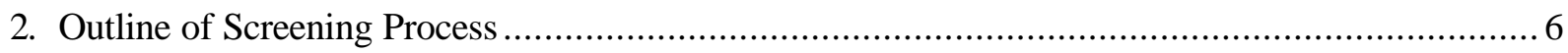

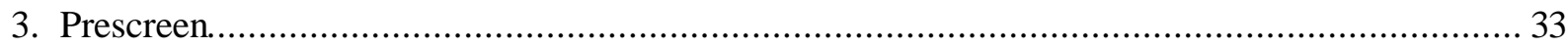

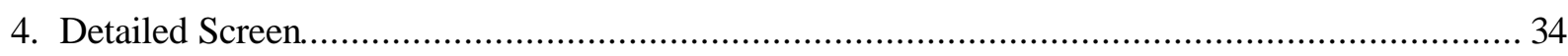

5. Dispatch Considerations under Multiple Goals .................................................................. 35

\section{Tables}

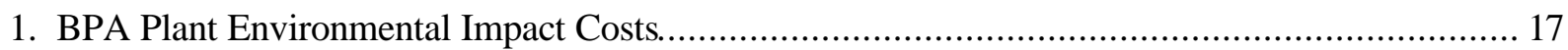

2. EPA Standards for Non-Road Diesel Generators with Capacities of $450 \mathrm{~kW}$ and Greater............ 19

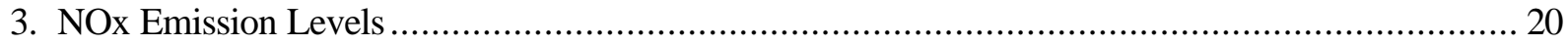

4. Value of DER Benefits with respect to a Partic ular Goal (\$/MWh) ....................................... 34

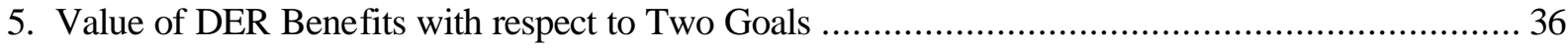

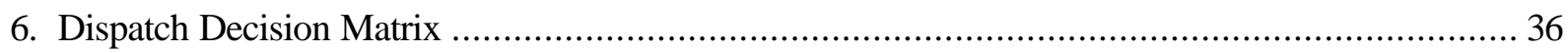




\subsection{Screening Criteria Overview}

This report describes a framework for evaluating candidate participants in a distributed resource aggegration program, as envisioned in the Bonneville Power Administration's (BPA) EnergyWeb initiative. The framework includes definition of system goals, relevant material that characterizes a distributed energy resource (DER) participant, rules for evaluating candidate participants, and a process that utilizes this information to produce a list of the most attractive candidates.

\subsection{Purpose}

BPA envisions an energy marketplace where significant amounts of distributed resources support the grid via an "energy web". BPA defines the EnergyWeb as the integration of distributed resources into the electric transmission and distribution system by incorporating advances in controls and telecommunications technology. The realization of EnergyWeb concepts is expected to enable an energy market that recognizes the locational value of resources and their effect on managing peaks and system reliability.

To advance BPA's understanding of the implications that applying EnergyWeb concepts may have to its system, they, together with other energy providers in the Pacific Northwest region, are developing a program of activities that includes creating a pilot system that integrates various DER (including generation, storage, and controllable load) to be operated for the benefit of the system. Coincidentally, the Load as a Resource research area of CERTS (the Consortium for Electric Reliability Technology Solutions) has the vision to "improve the performance of competitive electricity markets - while enhancing the reliability and security of the grid - through meaningful demand-side response to price or system conditions."

The objective of the work reflected in this document is to develop a set of screening criteria to help evaluate potential DER for participation in an EnergyWeb inspired system. To define reasonable screening criteria, the report highlights the importance of understanding the operational goals, the identification of relevant DER characteristics, and the definition of potential market products to which a pool of previously screened DER may be aggregated and economically dispatched.

The results of this work are directed at screening a number of potential DER candidates for participation in a resource aggregation program. Though the EnergyWeb initiative plans to initially aggregate a small number of DER in a pilot system, the characterization of potential resources and the issues that need to be confronted for a larger-scale deployment help in the definition of future plans for the EnergyWeb as well as provide a resource characterization framework for other CERTS Load as a Resource activities. In addition, the participation of a transmission system operator (BPA), a potential DER aggregator (Celerity Energy), and a distributed communications and control provider (Sixth Dimension) has kept the approach grounded in its consideration of real-world issues. 


\subsection{Approach}

The key to harnessing the system benefits of DER (including generation and load curtailment) is to engage large numbers of these relatively small resources into a significant source of aggregated energy. However, as the number of potential DER participants grows, the evaluation process becomes more complex. Picking and choosing participants for dispatch can create an energy mix that alleviates or aggravates a variety of system operational issues. To ensure a positive outcome, a screening process is put in place to assist in the evaluation of multiple resources for their value in addressing a combination of system issues.

An outline of this process is show in Figure 1. At the top are a number of DER candidates. These candidates are characterized by collecting information about their attributes (e.g., size, fuel, location). Each candidate's characteristics are passed through a coarse screening process, which compares each of the resource's characteristics against a set of thresholds (criteria) for participation. Candidates that meet this initial set of criteria then move into a finer screening process that uses sets of rules appropriate for each system need. Each resource's benefits are compared to the specific needs of the transmission and distribution system. (Note that a DER candidate can help address more than one system need, as discussed further in this report.) The result of this process is a series of lists containing candidate DER

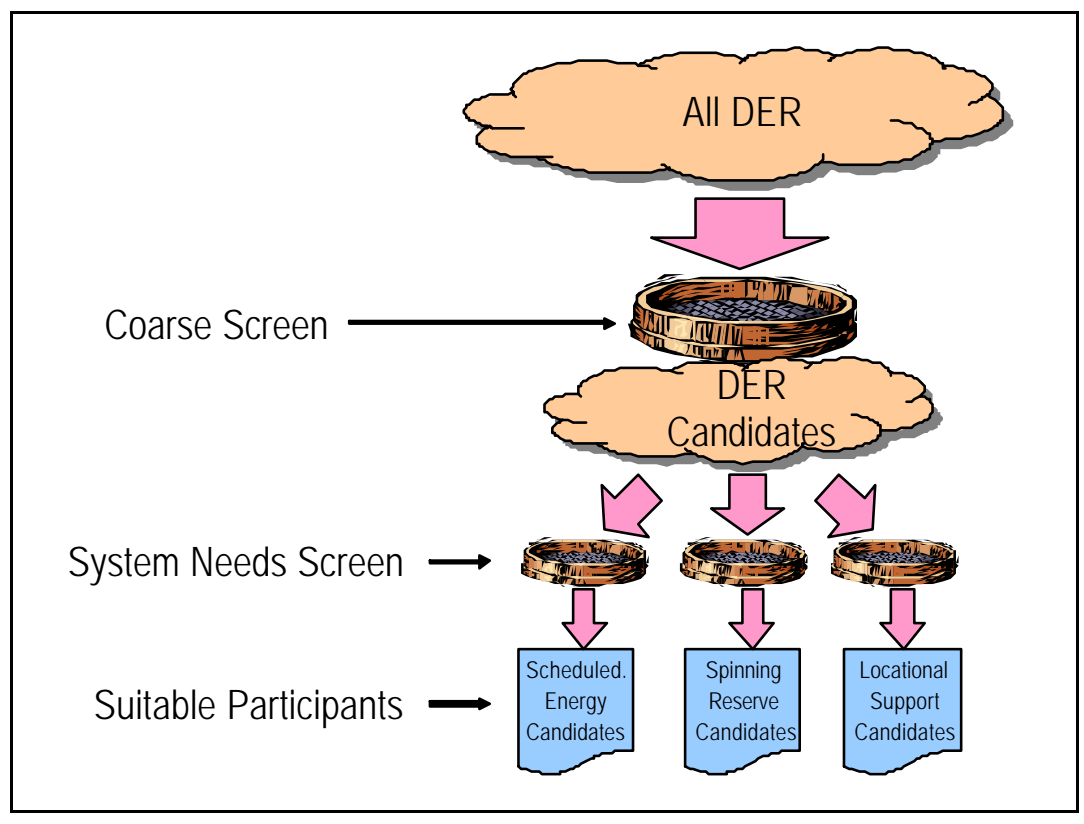

Figure 1. Screening Overview 
participants that can meet one or more system needs. As a final step, the suitable participants are ranked within each list according to weighting factors that highlight their attractiveness for the job.

While the result of this process is a list of candidate DER participants for an aggregation program, a somewhat different process is needed to effectively dispatch these resources. That is, under a specific operating scenario or emergency condition, the set of available DER to dispatch may change in response to a new situation-dependent ranking of the importance of quantity of energy required, air quality impact, energy price, and so on. This is a secondary, but related, outcome of the screening work. It is introduced later in this report in the section titled DER Dispatch Analysis Preview, and can be expanded upon in a future phase of the EnergyWeb program. 


\subsection{Screening Process}

The evaluation of candidate DER participants needs to follow a systematic process if it is to handle the expected relatively high number of candidates, and so that it can be refined as experience is gained and the EnergyWeb concept evolves. Figure 2 presents a series of steps envisioned as part of the screening process. The details of this process are presented in subsequent sections. A summary overview follows.

The process is divided into three phases: prepare, prescreen, and screen. The first item of the preparation phase is to identify the system goals. Understanding and articulating the system goals drives the remainder of the work. The goals must remain visible throughout the process if good decision-making is to prevail. From the system goals derive the market products that are the commercial instruments used to provide incentives to the marketplace to act in the desired manner. Examples of market products include day ahead scheduled energy and operating reserve. The commercial framework is reviewed with DER owners to identify candidates for the program. The system goals also provide the perspective for characterizing DER so they can be compared and evaluated against one another. This characterization is captured in the attributes of the DER. Examples of attributes include peak output rating and fuel used. Knowing the type of attributes desired for characterization, the DER candidates can be surveyed and develop a database of information with which to feed the screening steps to follow.

The prescreen phase represents the coarse grain screen discussed in the earlier section titled Approach. The prescreen looks across all system goals and chooses those DER attributes that can be confidently used to filter DER candidates from further consideration. Typically thresholds are associated with these pivotal attributes. If the prescreen thresholds are not met, the candidate is removed from further consideration. Examples of attributes with goal cross cutting thresholds include minimum power output capability and cost of integration of the DER into the aggregation program. The resulting prescreened pool of DER candidates is then fed into the detailed screening process.

After a prescreened pool of DER has been identified, the selection of DER candidates for use in meeting the system goals begins. The detailed screening process uses a set of rules defined for each of the system goals. The rule set for a specific system goal is applied to each DER candidate and results in a comparative evaluation for that goal. At the end of the evaluation, the DER candidates are ranked from most attractive to least attractive within each goal. Each DER candidate will likely have a different ranking for each system goal. Some goals may not be relevant to some resources; however no attempt is made to rank specific DER across different system goals as part of this participant screening process. Instead, BPA, local utilities, or aggregators can place targets for each system goal and select DER participants as needed to meet each goal target. 


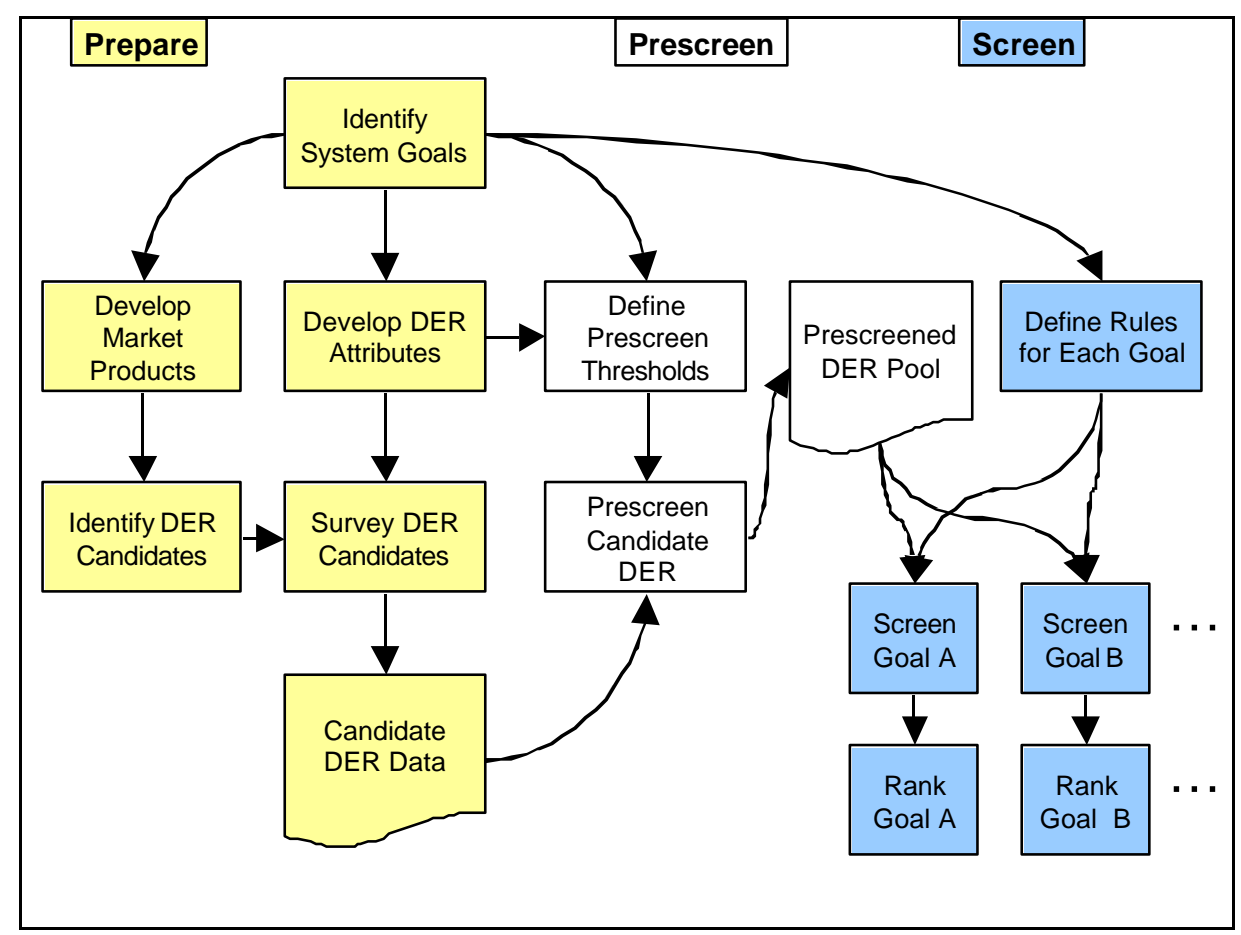

Figure 2. Outline of Screening Process

The complications involved with effectively utilizing a predetermined pool of DER can only practically be evaluated at dispatch time. Though the process for screening DER to participate in an aggregation program is related to DER dispatch, they should be treated as separate problems. This report focuses on the program participant screening issue; however, the operational dispatch issue is important to understand. A glimpse of the complications of effective DER dispatch is presented in the section titled DER Dispatch Analysis Preview. 


\subsection{System Goals}

Before the suitability of a specific DER can be evaluated for service in an aggregation program, the system needs or goals must be clearly articulated. The candidate DER participants are screened to ensure they can meet at least one of the potential system goals before being considered for joining the program. Initially, BPA indicates that they want to purchase low cost power, likely at periods of peak need. However, several other examples of goals have been mentioned, and some environmental goals or targets underlie the motivation for initiating the EnergyWeb concept.

Though examples are listed below, as EnergyWeb evolves, the goals will need to be clarified and solidified to enact effective screening tools. In addition, to realize these goals, the DER marketplace must be presented with effective incentives. The term "market product" is used to describe the contract or trading instrument used by those participating in the energy market.

\subsection{Example Goals}

Some examples of the system goals follow. Note that some of the goals can coincidently benefit BPA as well as the utility to which the DER is connected. Furthermore, some consideration must be given to the implementation of the environmental goals listed below. These typically are more difficult to justify economically; however, they represent important goals nonetheless.

\section{BPA Goals}
A. Affordable DER integration costs
B. Purchase competitively priced power
C. Ensure adequate operating reserve ${ }^{1}$

1. Spinning reserve (immediately available)

2. Operating reserve (available within 10 minutes)

D. Determine viability of DER to address intra-hour energy balancing requirements of renewable resources

E. Defer capital improvements to transmission network

1. Reduce "Path A" constraint

2. Alleviate transmission constraints to serve remote areas

\footnotetext{
${ }^{1}$ BPA defines operating reserve as the ability to cover the largest loss of generation contingency with $1 / 2$ spinning reserve and 1/2 reserve available within 10 minutes. BPA's Planning Group expects to be importing less power and exporting more in the coming years. To support this situation the operating reserve will need to grow from $\sim 2000$ MW today to $\sim 3000$ MW in the future.
} 


\section{Utility Goals}
A. Improvement of feeder voltage regulation
B. Defer capital improvements of feeder - lines, transformers or substations
C. Improved reliability - reduced frequency and duration of interruptions

1. Temporary power during repairs

2. Serve critical loads during disasters and system failures

D. Improved system capacity factor

E. Power and ancillary services purchases

F. Customer energy savings and power quality opportunities

III. Environmental Goals

A. Net benefit to the environment

1. Net reduction in emissions

2. Enhance management of river system

B. Enactment of policy targets

1. Provide incentive for $20 \%$ of new energy to be achieved by DER by 2010

2. Provide incentive to achieve a percentage of green power in system by 2005

3. Delay or eliminate construction of peaking power facilities

4. Delay or eliminate construction of new transmission and/or distribution lines.

Note that customers, DER owners and DER aggregators also have goals that need to be satisfied if an aggregation program is to be successful. From a system perspective, these are reflected in operational and policy goals just stated. To motivate participation of these stakeholders, cutomers desire reasonably reliable power with reasonable quality, at a reasonable price. DER owners desire to create or increase income from DER operation or diminish expense of owning DER, desire no negative impact to personal DER use (e.g., quality power or highly reliable power), and want low management overhead with any aggregation program participation. Aggregators want to generate profit from purchases and sales of aggregated resources to bulk and retail markets, while minimizing the expense to aggregate, operate, and maintain a pool of DER. 


\subsection{Goals \& Market Products}

To achieve the goals mentioned above using an open economy, BPA and the local utilities must enter into contracts and/or develop energy markets with instruments designed with these goals in mind. The form of these economic instruments will ultimately shape the nature of the participation irrespective of the goals. Defining these instruments and monitoring their effectiveness against the desired outcome will be critical to successful adoption of the EnergyWeb concept. The term "market product" is used to refer to these economic instruments.

Beginning with the example system goals, a few market products can be considered to encourage participation. For an aggregation program to attract participation that allows local utilities and BPA to purchase low cost power during peak periods (or reduce consumption), BPA can contract with a DER aggregator (e.g., Celerity Energy) to provide day-ahead power at an established rate (e.g., fixed rate, dayahead market rate, etc.). The terms and conditions and the price associated with this market product must be within the bounds of the cost-benefit analysis of both the buyer (say, BPA) and the seller (say, Celerity Energy, who is aggregating the cost-benefit of the DER participants). Analyzing the potential of various market products for EnergyWeb is a topic for future research.

Examples of other market products to achieve other system goals include:

- Operating Reserve Ancillary Service Market Product: Here a participant may be paid a flat rate to be "on call" in the event that actual energy is needed. Should actual energy be delivered, an additional payment scheme is agreed to ahead of time.

- Transmission Constraint Market Product: If the location of DER can help alleviate known transmission constraints, the day-ahead energy market product can be altered to include a regional component. DER in strategic locations may be offered additional financial incentives to participate in this market. This can be used by BPA or by a local utility to relieve a distribution feeder constraint.

- Intra-hour Balancing Service Market Product: Renewable resources, such as wind and solar, exhibit varying output on an hourly and daily basis. This provides challenges in meeting the transmission system requirements of balancing loads and resources on an hourly basis. If a renewable resource could "predict" its requirements for firm transmission service and fulfill its delivery obligations within the hours that the transmission services is secured, substantial penalties could be avoided in the form of intra-hour balancing charges levied by the transmission system. This intra-hour balancing service could conceivably be provided by a fraction of the DER generation that exists at a given wind or solar facility and could be provided anywhere within a given control area (verification needs to be done here). Additional analysis is required of renewable resource hourly and daily generation profiles to determine the optimal quantity of intra-hour balancing of DER resources to minimize penalties.

- Voltage and Reactive Power Support Ancillary Service Market Product: Though it is initially unlikely that the bulk transmission system can benefit from DER reactive power support, a local distribution system may be able to effectively address certain voltage problems. The appropriate 
instrument here may be a long-term contract that can call upon reactive power support on demand and would be based on the savings from deferring distribution equipment investments.

- Environmental Friendly Market Product: Setting up instruments to address these non-economicbased, environmental system goals becomes more difficult, primarily in deciding what is the costbenefit to the purchaser. In addition, addressing the letter of the contract may have undesired impacts elsewhere. For example, to reduce emissions, coalfired plants may raise their price of electricity, but with the undesired consequence that homes burn more wood for heat, thereby creating a dirtier environment than might have otherwise existed. Nevertheless, lower polluting DER can be offered additional financial incentive to participate in the scheduled energy market. Examples of such markets can reflect customer choice rates for green power or tradable emission credits for electricity production.

As a final note, individual DER may play a role in multiple markets to address multiple system goals, sometimes in synergy and perhaps in opposition. Identifying those that have synergies yield greater benefits, while DER that contribute in an opposing manner to system goals need to be somehow weeded out or given different incentives (see Interaction with Multiple Goals in the section titled Examples). 


\subsection{Rule Sets}

Rule sets are designed based on specific BPA, local utility, and environmental goals (as discussed above). For example, if a system need is to reduce congestion across a particular transmission path, a rule set can be made to "auto-filter" the remaining DER pool, eliminating all DER that cannot meet this system need by systematically comparing the DER attributes with the known requirements of the system goal. As the definition of these goals is still outstanding, a sampling of some of the more obvious ones is presented below for demonstration purposes.

\subsection{Prescreen Thresholds}

The prescreening of candidate participants is based on comparing key attributes to allowable thresholds. If any one of these thresholds is violated, the candidate is dropped from further consideration. Note, the threshold values can be adjusted to control number of candidate participants for further screening. Some thresholds may be "hard and fast", while others may be able to be compromised, particularly in the initial stages of creating a "critical mass" for an aggregation program.

Although a prescreen threshold is derived from a specific system goal, each is applied across all system goals. For example, a threshold on the speed of energy availability for the operating reserve goal should not be used in prescreening if it screens out legitimate participants for the scheduled energy goal.

Example prescreening thresholds follow:

I. Economic Power Thresholds
A) Minimum dispatchable output $>500 \mathrm{~kW}$
B) Minimum price for dispatch $<\$ 500 / \mathrm{MWh}$

II. DER Integration Thresholds
A) Maximum BPA cost for DER integration $<\$ 5000 / \mathrm{MW}$
B) Minimum communications link speed $>9600$ baud
C) Lack of electronic controls on distributed generating units

III. Environmental Thresholds

A) Maximum $\mathrm{NO}_{\mathrm{x}}$ for $500-\mathrm{kW}$ diesel generation $<10$ grams $/ \mathrm{kWh}$

B) Maximum particulate matter for $500-\mathrm{kW}$ generation $<0.6$ grams $/ \mathrm{kWh}$. 


\subsection{DER Integration Rules}

Besides considering the contractual or market costs of utilizing DER once it participates in an aggregation program, an upfront cost must be borne to integrate the DER into the system. Initially, a strict threshold can be placed on the amount of money an aggregator is willing to pay to integrate a DER site; however, as the EnergyWeb evolves, the integration cost should be compared to the monetary value of the expected benefit of the DER. For example, one DER could contribute to scheduled energy, operating reserve, and help relieve a transmission constraint. In that case, it may be worth more money to integrate it into the system.

Integration rules reduce to the cost of upgrading the DER site to meet the system interconnection requirements, as well as the communication and control needs. The costs for upgrading the site can be borne by the local utility, the DER owner, financial programs, or some combination of these entities. Determining the cost of integrating the candidate DER to meet these requirements can be complicated. To realize the EnergyWeb concept, realtime interaction with the DER is necessary. This means that appropriate communications and control must be available.

Sixth Dimension requires Internet access via a minimum 9600-baud phone line, wireless system, fiber optic circuit, etc. A relatively modern interface is needed for monitoring and controlling the equipment. This can be something like Modbus or LONWORKS. For older DER installations, installing gateways or upgrading the equipment to provide such an interface can address the issue. To avoid lengthy analysis, older systems can be filtered out of the process by a screen based on their age.

Celerity Energy is familiar with upgrading the DER sites to meet interconnection and environmental standards. This may involve upgrading the fuel system on a reciprocating engine to use natural gas in addition to diesel, upgrading synchronization equipment to handle closed transition ${ }^{1}$ transfers, installing isolation breakers, and upgrading protection schemes. In addition, a minimum number of sensors (transducers, status measurements) and actuators must be available to report on the status of the equipment and allow control of such things as generator startup and power output, as well as supervisory control of breakers. At a minimum, the power output is sampled every minute and the accumulated energy is captured every hour. The DER generation or curtailment must be controllable to set points. Furthermore, the DER must be able to be isolated (by remote control) from the rest of the system.

To streamline the integration costing process, a candidate DER can be surveyed for key information about what presently exists and what upgrade costs the responsible entity may be willing to bear to participate

\footnotetext{
${ }^{1}$ A closed transition transfer switch is equivalent to a make-before-break switch, allowing a generator to briefly operate in parallel with the utility ( $\sim 0.1$ second) before separating from the system. Such transfer scheme forces the generator to pick up load very quickly while paralleled, then quickly disconnect from the system. Alternatively, a dead-bus transfer connects a generator to a de-energized bus, requiring loads to be turned off prior to the transfer, but does not require synchronization.
} 
in an aggregation program. A relatively simple analysis could then be made to see if integration of the resource is worth pursuing. This can be explored further as a future work item.

\subsection{Economic Power Rules}

These rules are based upon the market products envisaged. From a screening perspective, a forecast of the $\$ / M W h$ that a DER can economically dispatch is necessary. This can be related to any of a number of scheduled energy markets (day ahead, 2 hour ahead, etc.). Beyond this threshold, more elaborate contractual rules may be put in place. For example, a base availability fee may be offered for the DER, allowing this energy to be dispatched at a set price. The penalty for not being able to meet a scheduled target needs to be established. Such agreements need to be negotiated, but the suitability of a candidate unit for dispatch can also be used as a screening criteria.

Additional criteria for screening can include availability and operating history attributes such as

- Startup time and ramp rate

- Minimum and maximum duration of operation (when called upon, and accumulated over a period)

- Maximum frequency of operation (e.g., times per month)

- Periods of availability (including permit hour limits)

- Age of generator

- Fuel availability and price.

\subsection{Operating Reserve Rules}

For DER that can contribute to operating reserve, the availability to respond to an emergency (generally during a peak load period) and the speed of response are important criteria. The type of DER is important here, although the relevant information is contained in the speed of response and availability attributes.

- Amount of energy immediately available and ramp rate

- Amount of energy available in 10 minutes

- Periods of availability

- Likelihood of availability (percent based on usage experience of the resource).

For reliability purposes, intermittent renewable technologies can be either removed from consideration for operating reserve contribution or de-rated in their capacity to account for the unavailability of the resource. To capture unavailability, one approach for renewable generation resources is to use a 
customary capacity credit (notated in \%). This is the same as a de-rating factor. For wind, depending on the wind power class, it can vary from 15 to $50 \%$. For solar photovoltaic (PV), it is simply a function of the ratio of daytime to 24 hours. Forecasting output from renewable resources is the subject of several studies by different organizations [e.g., Electric Power Research Institute (EPRI), National Renewal Energy Laboratory (NREL), and the European Commission's DISPOWER]. Wind is particularly complicated; large wind farms can have dramatically different characteristics from a single wind turbine.

\subsection{Transmission Constraint Rules}

Judicious use of DER may be able to alleviate transmission capacity issues and congestion that could otherwise lead to curtailments. For DER to play a role, these resources must be controlled on a location basis. Potential benefits of DER have been reviewed to address location-based issues for BPA and their utility customers. The use of DER to address dynamic or transient stability issues has not been explored at this time.

An example of an application of DER to alleviate transmission capacity issues exists today with the Puget Sound Naval Shipyard and the Bangor Submarine Base. Together, these two Bases can provide about 40 MW of additional capacity into the grid. These resources are currently being used to support the power system in winter peaking situations. Under the BPA Demand Exchange Program, the Navy views load levels and price signals from a BPA-supported web site and sheds load (separates to pick up local load) when warranted. This alleviates BPA transmission capacity problems in getting energy into the area. A major benefit to BPA is its ability to defer transmission expansion into this area.

The transmission constraint rule set must take into account the cost-benefit of using local DER to defer transmission expansion. This must be studied at a planning level; however, screens can be developed that utilize the electrical location of DER in the system. The concept is to construct a rule for each of the locations that experience transmission constraints. The BPA/local utility sub-regional designation would be used to screen for those DER that can help reduce the transmission constraint. Related attributes to such a screen would be the availability of the resource for the projected periods impacted by the associated transmission constraint.

BPA engineers also noted the following points concerning locational aspects of system operations and DER.

- Any additional scheduled energy located on the west side of the Cascades between Bellingham and Eugene can help winter peaking conditions.

- East of the Cascades, additional energy is not helpful because the system already has generation capacity in excess of that needed for scheduled exports to the west and south. With large industrial clients in the east curtailing or closing operations, and feeding their generation into the grid, there are already problems with too little demand for the available generation in this area.

- Mitigation of bulk transmission congestion will not be practical until the magnitude of DER is above the "noise level" of the transmission congestion in question (beyond $200 \mathrm{MW}$ of relief for 
north/south transfers of $\sim 7900 \mathrm{MW}$, and $100 \mathrm{MW}$ for the other system transfers). Below this level, the benefits for congestion relief cannot be readily observed.

- Location-based deployment of DER may potentially provide a benefit for planned outages on transmission systems by relieving loading on the remaining lines.

- DER may be able to mitigate the impact of congestion over specific paths. This is particularly true on coastal areas, where a few megawatts of capacity can make a big difference (some possible examples follow):

○ Coos Bay

- Lower Valley - Jackson Hole/Fall River Electric Coop (Southeast Idaho). Although there is a new transmission line, the load growth is such that the capacity of this line will be quickly equaled and exceeded.

- Mendenoca/Raft River (area in southern Idaho)

- Olympic and Kitsap Peninsulas. Under a loss of transmission corridor contingency.

○ Northwest to Idaho congestion

- Harney County (SE Oregon) has a heavily loaded $115-\mathrm{kV}$ line with a summer peaking situation and a large pumping load.

For each situation where the locational deployment of DER is considered, the amount and desirable location of DER that alleviates the problem would be studied. A rule set would then be constructed to select the appropriate resources from among the candidates. Financial weightings can be assigned to each location (much like locational marginal pricing schemes), where greater benefit is recognized to DER in the most advantageous locations.

\subsection{Feeder Voltage Regulation Rules}

DER may also be able to alleviate some voltage problems on the system (Lasseter et al. 2002, Key 2001). Initial research shows that at this stage, the penetration of DER is unlikely to provide reactive support to the transmission system. This is the result of the impedance between the DER and the transmission level, competition with other voltage regulating devices, and the fact that low voltage leads to high current needs, which implies high $\mathrm{I}^{2} \mathrm{X}$ losses. However, from a distribution utility perspective, if DER is located some distance down long feeders, they can be used to "prop up" voltages at the end of the line. This is beneficial even if the DER delivers only real power. If this is the case, knowing the position of the DER within the distribution system is important. If reactive power can also be controlled, a DER can improve voltage even at the head of the feeder system. Knowing the MVAR support available is important in this case.

Expanding the scope of the EnergyWeb to select DER only for feeder voltage regulation is not recommended; however, DER that can supply energy into the system, as well as support regulation 
voltage in remote parts of the distribution system, can be ranked higher because of the greater overall system benefit of these resources.

\subsection{Environmental Impact Rules}

BPA's two environmental related objectives are a net reduction in emissions and achieving a net benefit to the environment. By placing economic values on generators that negatively impact these objectives, the cost-benefit analysis can internalize the costs of environmental impacts and will tend to make more benign technologies more competitive on a cost basis. This approach was precisely the method incorporated in BPA's resource evaluations, as described in the Resource Program Environmental Impact Statement (EIS) (BPA 1993). The EIS states (page 5.51) that The Pacific Northwest Electric Power Planning and Conservation Act defines system cost as:

“... an estimate of all direct costs of a measure or resource over its effective life, including, if applicable, the cost of distribution and transmission to the consumer and, among other factors, waste disposal costs, end-of-cycle costs, and fuel costs (including projected increases), and such quantifiable environmental costs and benefits as the Administrator determines, on the basis of a methodology developed by the Council as part of a plan, or in the absence of the plan by the Administrator, are directly attributable to such measure or resource."

The EIS also states that "system costs consist of two components: direct costs, and environmental externality costs. Direct costs are borne by a regional party (such as BPA, a utility, or consumers)...Environmental externalities are the economic costs and benefits that are not directly borne by the party causing the environmental effect."

Difficulties in implementing these economic principles for the DER lay in discrepancies between approaches and information suitable for large power plants in comparison with smaller generators, and applying generic rules to specific generators.

For planning purposes, BPA established environmental impact costs for power plants, as shown in Table 1. These costs are intended to account for comprehensive environmental impacts, not just emissions. These costs were established for large-scale power plants and may not directly apply to smaller generators. Emission data, fuel variability, and pollution control for smaller plants is less understood than for large generators. Furthermore, the regulatory structure for acquiring generator licenses and permits varies greatly from state to state, and sometimes from air district to air district. 
Table 1: BPA Plant Environmental Impact Costs

\begin{tabular}{|l|c|}
\hline Resource Type & $\mathbf{1 9 9 0}$ mills/kWh \\
\hline Coal & 5.1 \\
\hline Coal (fluidized bed) & 3.0 \\
\hline Coal (coal gasification) & 2.6 \\
\hline Simple-cycle combustion turbine (CT) & 1.5 \\
\hline Combined-cycle CT & 1.4 \\
\hline New hydro facility & 2.0 \\
\hline Natural gas cogeneration & 1.2 \\
\hline Additions to existing hydro & 1.0 \\
\hline Geothermal & 1.0 \\
\hline Wind & 0.5 \\
\hline Solar & 1.0 \\
\hline Conservation & 0 \\
\hline Wood-fired cogeneration & 3.8 \\
\hline Municipal solid waste-fired cogeneration & 7.9 \\
\hline Nuclear & 2.0 \\
\hline
\end{tabular}

\subsubsection{Power Plant Siting and Review}

States typically set up special commissions and criteria to license power plants of a defined capacity. The threshold capacity for licensing varies from state to state. Following are the thresholds for the Northwest states and California and a brief description of review processes.

- California: $50 \mathrm{MW}$

- Idaho: Not applicable - Idaho only reviews hydropower facilities

- Montana: $50 \mathrm{MW}$

- Oregon: $25 \mathrm{MW}$

- Washington : $250 \mathrm{MW}$.

California, Montana and Washington require an environmental impact analysis for energy facilities. These analyses are based on State Environmental Policy Act (SEPA) requirements modeled after federal National Environmental Policy Act (NEPA) statutes. These are referred to as "full disclosure" laws. In such a process, facility approval is based on a detailed level of information supporting more broadly worded criteria, such as "acceptable environmental impact." 
Oregon's review process is "standard based," meaning the decision is based on an assessment of evidence against specific standards in the rules. This is consistent with Oregon's decision in the early 1970s to embrace specific land use criteria rather than a SEPA.

The Oregon Office of Energy has prepared a description of each of the Northwest states' and California's review processes. See http://www.energy.state.or.us/siting/sitecom.htm for more information on environmental review requirements.

The need to access generation during energy emergencies has been recognized by state governments. This was evidenced recently in California, where generators in certain air districts relaxed operating standards during stage 3 emergencies. In Washington, some generators were allowed to begin operations before being fully certified, and others were temporarily allowed to exceed pollution limits, although the increased pollution was to be offset with later reductions. Oregon has adopted a policy to streamline the air quality permitting process for new power plants. Oregon intends to regulate distributed generation using permits (http://www.deq.state.or.us/aq/generators.htm) and would allow generation without permitting in the event of a declared energy emergency.

The review and siting processes apply only to large-scale power plants, as defined by state legislation. Small-scale generators are much more on their own, and there are no centralized, one-stop shopping agencies that can provide comprehensive information about each generator. Each developer is responsible for securing permits and approvals in areas such as land use, building codes, electric codes, seismic codes, air quality, water quality, wetlands, reliability, hazardous materials, and so on. The California review process investigates 19 specific technical areas.

In California, individual air districts may impose more severe emissions criteria than those required by the state. California has established permit assistance centers to help businesses of all types acquire needed air quality and other environmental permits. A lawyer at the California Energy Commission (CEC) also indicated that the CEC might coordinate siting for small generators if requested to do so.

\subsubsection{Impact Assessment}

The environmental information developed for large-scale power plants is not directly applicable to distributed generators. Generation efficiencies tend to be less for distributed generators than for largescale power plants, and emissions tend to be greater. On the beneficial side, less land is typically needed to site the generators, and the units probably do not impact visual resources. However, the plants may be located in areas not well suited to noisy generators, such as commercial districts or near hospitals.

The greatest air quality concern is associated with diesel fuel generators. The U.S. Environmental Protection Agency (EPA) regulates emissions from portable diesel generators (EPA 1998). The EPA has structured a three-tier standard that is being phased in from 1996 to 2008. The EPA notes that the rule will reduce $\mathrm{NO}_{\mathrm{x}}$ by $50 \%$ and particulate matter $(\mathrm{PM})$ by $16 \%$ by the year 2020 . In the near term, however, much needs to be done to reduce emissions from existing engines if state air quality goals are to 
be met (EPA 2001). Achieving emissions reductions from in-use diesels is needed because older engines pollute at much higher rates than newer ones because of deterioration and less stringent emission standards. A distinction should be made in selection criteria between older and newer diesel engines. Non-portable diesel engines are not covered by the regulation. Thus, criteria should specify that all engines meet the standards. Table 2 summarizes the EPA standards.

Table 2: EPA Standards for Non-Road Diesel Generators with Capacities of $450 \mathrm{~kW}$ and Greater (Adapted from Gregerson and Van Holde 2001, based on EPA 40 CFR, Parts 9, 86, and 89, Table 1)

\begin{tabular}{|c|c|c|c|c|c|c|c|}
\hline & & & \multicolumn{5}{|c|}{ Grams per kWh } \\
\hline Tier & $\begin{array}{l}\text { Model } \\
\text { Year }\end{array}$ & Engine Power & $\mathrm{NO}_{\mathrm{x}}{ }^{\mathrm{a}}$ & $\begin{array}{l}\text { Hydro- } \\
\text { carbons }\end{array}$ & $\begin{array}{l}\mathrm{NMHC}+ \\
\mathrm{NO}_{\mathrm{x}}{ }^{\mathrm{b}}\end{array}$ & $\mathrm{CO}$ & $\mathrm{PM}^{\mathrm{C}}$ \\
\hline \multirow[t]{2}{*}{1} & 1996 & $<=450$ to $560 \mathrm{~kW}$ & 9.2 & 1.3 & & 11.4 & 0.54 \\
\hline & 2000 & $>=560 \mathrm{~kW}$ & 9.2 & 1.3 & & 11.4 & 0.54 \\
\hline \multirow[t]{2}{*}{2} & 2002 & $<=450$ to $560 \mathrm{~kW}$ & & & 6.4 & 3.5 & 0.2 \\
\hline & 2006 & $>=560 \mathrm{~kW}$ & & & 6.4 & 3.5 & 0.2 \\
\hline 3 & & $<=450$ to $560 \mathrm{~kW}$ & & & 4.0 & 3.5 & \\
\hline
\end{tabular}

${ }^{a}$ In Tier $1, \mathrm{No}_{\mathrm{x}}$ and hydrocarbons are specified independently.

${ }^{\mathrm{b}}$ In Tiers 2 and 3, the standard regulates the sum of $\mathrm{NO}_{\mathrm{x}}$ and non-methane hydrocarbons (NMHC)

${ }^{\mathrm{c}}$ The Tier 3 particulate matter standard was not specified at time of table generation.

The California Air Resources Board (CARB) has established guidelines for regulating stationary diesel engines. Air districts may adopt these standards. The CARB guidelines recommend that all new stationary, diesel engines greater than 50 horsepower, used for economic dispatch, emit no more than 0.1 grams of PM per horsepower per hour. Emissions of $\mathrm{NO}_{\mathrm{x}}$ are equivalent to those of the EPA standards for non-road diesel engines. Emergency-standby engines are allowed to operate during emergencies and for a total of no more than 100 hours per year. Engines operated for non-emergency backup or longer than 100 hours per year should use very low-sulfur fuel (sulfur content not to exceed $15 \mathrm{ppm}$ ), and be equipped with a catalyst-based diesel particulate filter.

Diesel fuel types can greatly influence emission (EPA 1999). The EPA does not currently regulate diesel fuel sold for use in non-road equipment. Typical non-road diesel fuel meets ATM specification D975, which sets a maximum sulfur level of 5,000 ppm. This fuel type commonly contains sulfur levels up to $3,000 \mathrm{ppm}$. Sulfur in diesel fuel is corrosive, and sulfur dioxide is regulated as a criteria air pollutant. Sulfur contributes to increases in particulate emissions, which the EPA has classified as probable human carcinogens. Highway diesel fuel is regulated and has a maximum sulfur content of $500 \mathrm{ppm}$ with typical average fuel levels of $300 \mathrm{ppm}$. Many non-road equipment users choose to operate their engines using highway fuel.

Table 3 offers a comparison of $\mathrm{NO}_{\mathrm{x}}$ emission levels from a variety of generation resources. 
Table 3: $\mathrm{NO}_{\mathrm{x}}$ Emission Levels (adapted from Gregerson and Van Holde 2001)

\begin{tabular}{|l|l|}
\hline Resource Type & $\mathbf{N O}_{\mathbf{x}}$ (g/hp-h) \\
\hline Natural gas fuel cell & 0 to 0.007 \\
\hline Micro turbine & 0.14 to 0.61 \\
\hline Combustion turbine & 0.1 to 1.3 \\
\hline Natural gas engine & 0.55 to 8.95 \\
\hline Diesel engine & 1 to 10 \\
\hline Existing diesel emergency & 8.47 to 11.86 \\
\hline $\begin{array}{l}\text { New Calif. combined-cycle } \\
\text { combustion turbine (CCCT) }\end{array}$ & 0.02 \\
\hline Existing Calif. gas-fired & 0.17 \\
\hline Coal (fluidized bed), controlled & 0.14 \\
\hline Coal (fluidized bed), uncontrolled & 0.71 \\
\hline Coal controlled & 0.31 \\
\hline Uncontrolled coal & 2.2 \\
\hline Natural gas, phosphoric acid fuel cell & 0.01 \\
\hline $\begin{array}{l}\text { CT dry low emissions with selective } \\
\text { catalytic reduction (SCR) }\end{array}$ & 0.11 \\
\hline CT dry low emissions & 0.27 to 0.35 \\
\hline Uncontrolled CT & 1.3 to 2.7 \\
\hline New diesel EPA Tier 1 with SCR & 0.69 \\
\hline New diesel EPA Tier 1, uncontrolled & 6.9 \\
\hline
\end{tabular}

\subsubsection{Accounting for Specific Conditions}

Externality costs developed for generic resources do not take into account specific local conditions or mitigation incorporated for each power plant. For example, a generator may have mitigated its air pollutants by acquiring offsetting credits from other polluters in the same proximity. In comparison with another identical plant that was not required to acquire such offsets, or even a cleaner plant without offsets, the example plant may be the most benign. To further complicate this scenario, mitigation may be incorporated for some effects but not for others. For example, wetlands may be purchased and preserved to offset placing a generator in a sensitive environment, but this does not account for air emissions. Or, carbon offsets may be purchased, while no offsets for other pollutants are purchased. Thus, externality costs may need to be adjusted to accommodate varying technology efficiencies, regulatory differences in air districts and states, and voluntary mitigation incorporated into plant designs. One response to the lack of regulatory consistency and plant-specific technology and design issues would be to establish a two-step process. The first step would be to include environmental criteria in site 
inspection visits and generator applications. To the extent possible, the inspector should establish the status of obviously needed permits for the plant and permitted operating parameters and efficiencies. If a plant is permitted, it should be assumed that state and local agencies are ensuring that conditions of the permit are followed. It would be extremely difficult to ensure that all regulatory requirements have been met. The second step would be to establish conservative estimates of impacts and base externality costs on those estimates. Individual generators could provide additional information if they wish to receive a more favorable rating or price for selection criteria. This approach is consistent with the 1993 methodology, which states that the "BPA (externality) adjustments are for default emission rates. Specific plants with emission rates different than the default rates are assigned different adjustments." 


\subsection{Ranking}

After the prescreening and detailed screening rule sets have been applied, the resulting DER pools represent all possible candidates for participation. The remaining task is now to ensure that the dispatch of one or more of the DER in each pool will provide satisfactory economic benefit. By ranking the DER in order of the benefit they provide, the process can then select the most attractive participants for each rule set.

Generally speaking, this will be done using a form of cost-benefit analysis. Each system goal has a price that the transmission owner is willing to pay to meet that goal. Against this are the costs associated with implementing a DER unit to meet the system goal. The abbreviated process is described as follows:

- $\quad$ Define the value associated with each system goal.

- $\quad$ Establish the economic value for each DER attribute (including environmental externality values).

- $\quad$ Rank the available DER based on a cost-benefit type of analysis.

If, for example, 100 DER units are candidates to meet a particular system goal, they can be ranked in decreasing order of their economic value with respect to the threshold value for that goal. The energy aggregator will begin at the top of the list and sign up participants until the established targets are reached or until DER units no longer meet the threshold value for that goal.

In some cases, a single DER may contribute to more than one system goal. For example, if one system goal is to reduce a constraint on "Path A" transmission (and it is valued at $\$ \mathrm{x} / \mathrm{MWh}$ ), and another is to contribute to scheduled energy (and it is valued at $\$ y / M W h$ ), a single DER could meet both system goals if it meets or exceeds the threshold values for each goal. In this example, the DER unit may not necessarily rank first for either of the system goals, but when both goals are considered together, the DER would clearly win.

In contrast to the above example, consider the hypothetical case where the DER is ranked first with respect to one of the system goals but is eliminated when screened for another goal. Referring back to the previous example, if one system goal is to contribute to scheduled energy, and another is to reduce a constraint on "Path A" transmission, a DER may win first place in the ranking of the first goal at the expense of further overloading "Path A". If the system goals are evaluated independently, the DER is selected to contribute to scheduled energy. But if the goals are considered together, the ranking and selection for dispatch of the DER is not obvious.

To adequately address these combinatorial issues, the process for selecting program participants must be adapted to a process for selecting DER to dispatch (see section titled DER Dispatch Analysis Preview, below). For simplicity, the participation selection process may be designed to ignore such issues. 


\subsection{DER Attributes}

To apply the screening rules, each DER is characterized by a set of attributes. The following attributes provide adequate information to process the rules identified in the preceding section, Rule Sets. Consider these as an initial set of attributes. New rules or interest in tracking other information will cause this list to expand. On the other hand, initial experience in trying to obtain information from a few sites with DER suggests that the majority of this information is not easily available. The practical solution will likely emphasize the few, distinguishing attributes that reasonably support a prescreen threshold for participation and subsequent priority ranking for each system goal. Other experiences surveying DER sites (see Goldman, Heffner and Kintner-Meyer 2002) suggest that the screening criteria should be defined such that distinguishing characteristics can be revealed with a minimal amount of information.

A refined set of attributes can be determined through a survey and interviews with potential participants.

\subsection{General Attributes}

The following information is collected for general power support issues.

I. Owner/Operator Information
A) Owner name
B) Address and contact information
C) Organization type
1) Municipality
2) Power park association
3) Industrial
4) Commercial building

II. DER Type

A) DER manufacturer, make, and model number

B) Primary purpose

1) Primary electric supply

2) Combined heat and power

3) Backup and reliability

4) Load management (includes price hedge and speculative energy) 
C) Generation and fuel

1) Reciprocating: diesel, gas, dual (diesel, gas), bio-mass

2) Hydroelectric

3) Combustion gas turbine

4) Photovoltaic

5) Wind

D) Elastic demand (curtailable load)

1) Resistive

2) Motor

3) Other

E) Storage

1) Battery

2) Compressed air

3) Pond

4) Other

III. Energy Size and Price
A) Nameplate rating (MW)
B) Peak rating (MW and duration)
C) Minimum dispatchable output (MW)
D) Minimum price for dispatch ( $\$ / M W h)$
E) Curtailable load profile
1) Summer, winter, and spring/fall
2) Available each hour

IV. Availability
A) Startup time and ramp rate
B) Does operation rely on other plant processes (such as shared cooling or lube oil systems, or fuel pre-processing like bio-mass)?
C) Does operation depend on renewable sources being available (e.g., solar, wind)? 
D) Periods of the day, week, or year the generation or load curtailment is expected to be unavailable

E) Maximum frequency of generator operation or load curtailment (times per month)

F) Minimum and maximum duration of operation (when called upon, and accumulated over a period)

G) Is the unit configured to support black start procedures?

H) Air permit operating limits (also see section titled Environment)

V. Operating History

A) Is the generator typically operating? If yes, what is the marginal rating?

B) Forced outage history

C) Running design criteria (e.g., is nameplate rating based on reduced annual operation?)

D) Age of generator and expected remaining life (from operating history and maintenance records)

E) Monthly/annual fixed operations and maintenance $(\mathrm{O} \& \mathrm{M})$ costs.

\subsection{Location}

DER is usually sited to support the regional needs of the owner; however, the resources may also be beneficial for addressing problems on the distribution feeder or in the bulk transmission area that feeds the distribution system. For general transmission level power support, knowing the region and available power (from previous attributes) is all that is needed. For situations that may require voltage support, a more complex set of information is needed. As a result of these complications, DER has not so far been considered for reactive support; nevertheless, it represents an area for potentially valuable research. Item B below suggests some attributes that may be significant contributors to determining the effectiveness of a DER for voltage support.

VI. Location Attributes

A) BPA/local utility regional designation

B) Contribution to voltage support (Lasseter et al. 2002, Key 2001)

1) Dispatchable MVAR

2) Location on feeder: A DER, even without reactive capability, can be effective with low voltage problems at the end of a distribution feeder if it is located some distance down the feeder. Reactive support at the supply point of the feeder may also be helpful.

3) Is there an LTC (load tap changing) transformer upstream of the interconnection? If DER is to supply reactive support to the transmission system, understanding the interaction with voltage control transformers, capacitor banks, and other reactive controls needs to be studied. 
4) Impedance between the DER and the transmission grid: This parameter will impact the influence that DER will have on the transmission system (e.g., voltage support). More research is needed to study the correlation.

\subsection{Environment}

VII. Environmental Attributes

A) Emissions

1) Type of emission measured $\left(\mathrm{NO}_{\mathrm{x}}\right.$, hydrocarbons, $\left.\mathrm{NMHC}+\mathrm{NO}_{\mathrm{x}}, \mathrm{CO}, \mathrm{PM}\right)$

2) Concentration (two numbers if dual fuel)

3) Permitted emissions $\left(\mathrm{NO}_{x}\right.$, hydrocarbons, $\left.\mathrm{NMHC}+\mathrm{NO}_{\mathrm{x}}, \mathrm{CO}, \mathrm{PM}\right)$

4) Emissions-based operational restrictions

5) Regional restrictions

6) Estimated costs for improved generation exhausting (some emergency generator installations did not consider proper building exhausting for more general use operation)

B) Noise

1) DB level at various times of the day

2) Estimated costs associated with noise abatement mechanisms

C) Ground water abatement: Estimated environmental protection costs of storage and contingencies for leaks

D) Decommissioning: estimated cost of bonds to ensure land and space is restored to local authority's satisfaction.

\subsection{Communications and Control}

The following information relates to the integration of the interactive measurement and control of DER. The lack of accessibility to reasonable communications methods or the necessity to support a very specialized equipment control interface may make integrating the DER prohibitive.

VIII. Communications and Control Attributes

A) Control communication

1) Remote, automated control 
2) Manual control interface (phone, e-mail, or Internet)

B) Availability of Internet access (twisted pair, wireless to support 9600 baud or above)

C) Controller interface (e.g., LAN running Modbus or LONWORKS). Need a controls interface that is modern enough to make automation economically viable

D) Control parameters (e.g., power output, voltage, VAR, or power factor control)

E) Analog measurement feedback (e.g., generation power output, voltage, frequency - every minute, energy - every hour). The amount of load at the site also needs monitoring - every minute. This may be needed to record load reductions or to determine the capability of a distributed generator to pick up this load when a site disconnects from utility service. The accuracy requirement for this equipment (e.g., revenue grade meters) must be noted and its costs considered.

F) Status measurement feedback (e.g., switch position, low battery, low fuel warning, alarm conditions - every minute).

\subsection{DER System Integration}

Before DER can participate in an aggregation program, it must meet the appropriate interconnection standards. Presuming that the aggregator is responsible for the integration of the device, an estimate of the expense to upgrade the DER site so that it can participate in the program can be an important contribution to determining the attractiveness of a candidate. If these costs are borne wholly by the owner, then the cost may not be relevant.

\section{Integration Upgrades}

A) Interconnection standards - these requirements can determine the type and quality of equipment needed to integrate the resource, thus affecting the cost.

1) Common requirements of all DER

2) Regional requirements (determined by appropriate electric company)

B) Synchronous operation - this mode of operation requires more sophisticated integration, and can potentially contribute to additional system goals.

1) Automated synchronization switchgear

2) Contribution to spinning reserve

3) Contribution to reactive VAR support

C) Disconnected operation

1) Automatic transfer switching (dead bus transfer or closed transition switch)

2) Telemeter acknowledgement (e.g., status of disconnect breaker) 


\section{D) Finance}

1) Estimated cost to integrate the resource
a. Generator upgrades
b. Engineering; design, start-up and testing
c. Equipment (paralleling switchgear; controls; emissions controls; communications)
d. Installation [labor; materials (i.e., conduit, conductor, etc.)]
e. Site improvements for exhausting, noise, and other environmental considerations

2) Willingness to co-fund upgrades for participation 


\subsection{DER Dispatch Analysis Preview}

Thus far our focus has been to develop a process and screening criteria for evaluating candidate DER to participate in an aggregation program. As seen in section titled Ranking, the rules for efficient DER dispatch, in an operational sense, become complicated when one attempts to rank resources across all relevant system goals. For addressing a single system goal, an aggregator can rank DER much as described in the earlier section. For example, suppose the dispatch of three DER provides potential economic benefit. If only two DER are needed to meet the goal, then the DER will be dispatched in the order in which they are economically ranked, and the third would not be called upon to contribute. Now suppose that our pool of DER is available to address multiple system goals. Individual DER may work in synergy or opposition to these goals and the ranking of DER for each set of system goals is not adequate for an overall, effective DER system dispatch.

A complete analysis of and proposal for an approach for DER dispatch is beyond the scope of this study. This issue should not pose a problem for aggregating DER in an EnergyWeb pilot prototype. However, as full-scale aggregation evolves, an appreciation of the issues for effective system dispatch will become important for DER aggregators. In addition, by sketching an initial picture of DER dispatch, the boundaries between program participant selection and system operational issues become better defined.

An important characteristic to DER dispatch is the time varying nature of the objective function. At different times of the day, week, and season, different system goals become more dominate than others. Although patterns emerge, the mix of issues continuously changes. For example, at peak loading conditions, the priority goal may be to obtain more generation, even if it temporarily compromises environmental goals. Similarly, at different times of the year, different transmission segments may become constrained. As the priorities of these transmission constraints change, the desired DER locations for dispatch change.

Planning for dispatch must not only forecast the system needs, but also review the availability of each DER for the time period in question. The dispatcher must be able to view the extent of the aggregated DER pool and have tools to automate the process of selecting those resources that can be brought to bear to best meet the forecasted system needs. The following list considers those DER characteristics that are systemic in nature.

\section{Systemic Characteristics}

A) Dispatchable shape of aggregated DER

1) Considers DER availability (renewable, emission limitations, contracted durations)

2) Hourly, weekly, seasonally

3) Ramp rate of aggregated response

B) Cross coupling between different DER 
1) Precedence relationships

2) Exclusions

3) Required parallel or coordinated operation

C) Financial position of the aggregated resources (if aggregator's responsibility)

1) Overall operation and maintenance cost and revenue of committed resources

2) Incremental cost and revenue

D) Overall incremental environmental impact

1) Regional view of amount of emission in various categories

2) System-wide view of amount of emission in various categories

3) Avoided impact from alternative bulk resources

E) Overall locational benefit

1) Constraint management

2) Voltage support

The section Interaction with Multiple Goals demonstrates how resources that can positively impact several system goals may go to the head of the dispatch list, even if they are ranked as mediocre on individual goals. 


\subsection{Examples}

Two examples are provided in this section to show how a DER selection process could occur. The first example demonstrates selecting aggregation program participants by looking at the results of prescreening and an individual rule set (representing a singular system goal). The ranking for this example is similar to the single objective DER dispatch case. Having only one goal simplifies the selection process because a DER cannot provide both benefit and detriment to a single objective.

\subsection{Singular Goal}

System goal: Reduce transmission constraint at "Path A"

The first step in the process is to identify the pool of DER resources that are available for use in this project. A coarse screen is first used to sift out all the DER units that do not pass some minimum threshold required for program participation. The screening criteria will likely be based on several different issues, but the primary idea is to reduce the DER selection pool to a relevant set of units, thus allowing manageability.

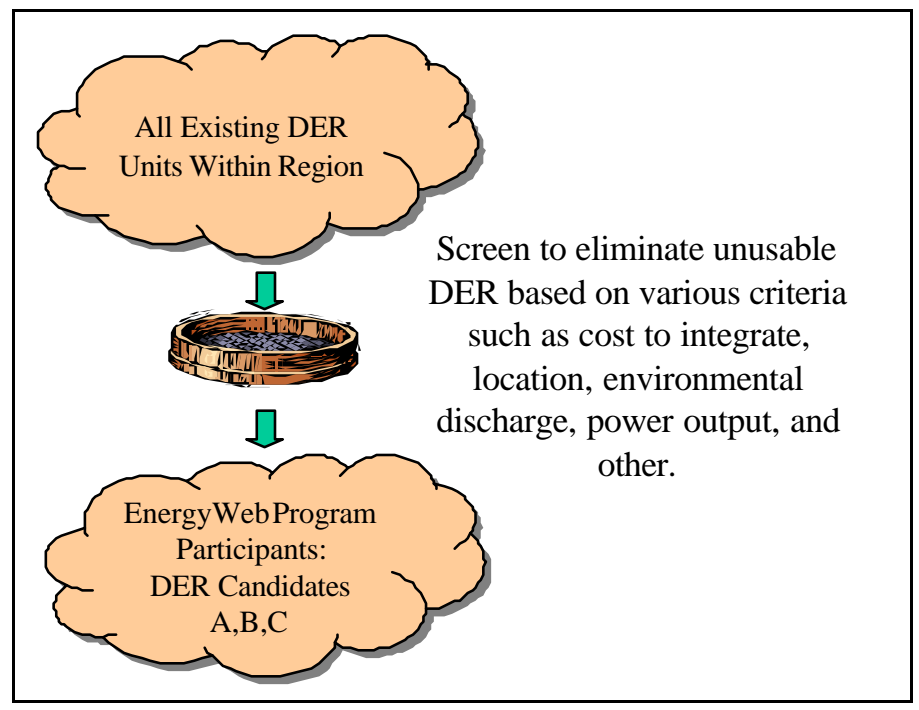

Figure 3. Prescreen

Once a pool of DER candidates has been identified, they can be filtered again and have a rule set applied to them that is tailored to meet the needs of a particular system goal. 


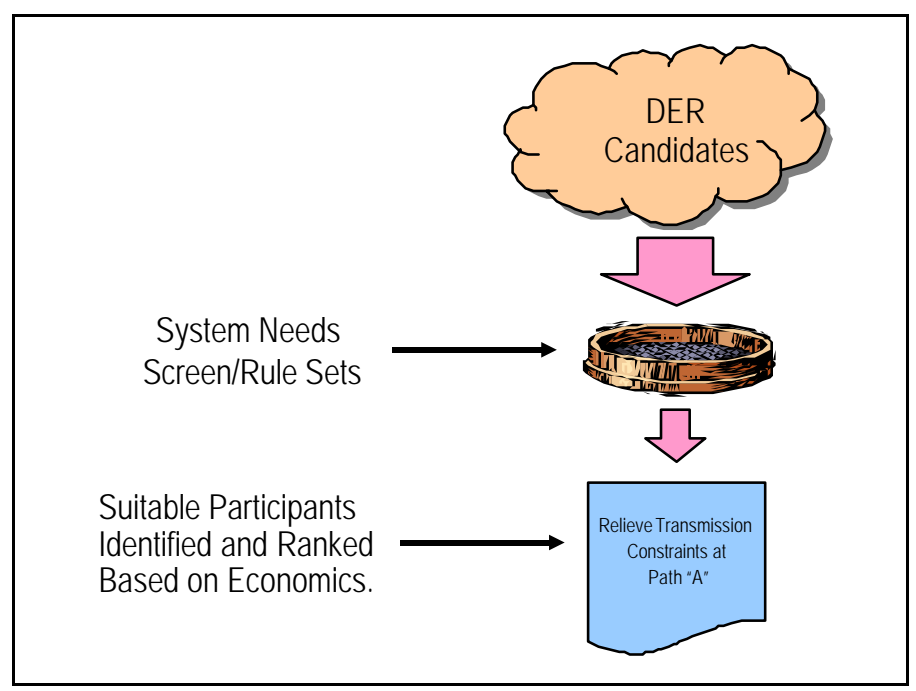

Figure 4. Detailed Screen

For the system goal in this example, the attributes of each DER are compared with the needs of the goal. The comparison goes beyond a pass/fail criterion, and allows each attribute of the DER to be economically quantified with respect to the system goal it is intended to meet. Sufficient details regarding the location of this "Path A" transmission constraint and the location of the DER are contained within the database such that an economic evaluation can be made for each DER unit regarding its location with respect to its ability to accomplish the system goal.

The same analytical process continues with other DER attributes, such as time of availability, emissions, and possibly bid price. An example of 'time of availability' might be that the DER contract would not permit use during certain peak hours. Thus, the probability of needing to dispatch the DER during this 'closed time' would be reflected in a negative economic evaluation. Similar analyses would be done for remaining attributes of relevance, such as emissions. The column labeled bid price may or may not be relevant, but leaves the option for an economic evaluation for a bidding process, whether real-time or scheduled (see Table 4).

Table 4: Value of DER Benefits with respect to a Particular Goal [\$/MWh]

\begin{tabular}{|c|c|c|c|c|}
\hline Unit & Location & $\begin{array}{c}\text { Time of } \\
\text { Availability }\end{array}$ & Emissions & Bid Price \\
\hline A & $\$ 50$ & $-\$ 5$ & $-\$ 20$ & $\$ 30$ \\
\hline B & $\$ 30$ & $-\$ 8$ & $\$ 30$ & $\$ 40$ \\
\hline C & $\$ 40$ & $\$ 0$ & $\$ 12$ & $\$ 50$ \\
\hline
\end{tabular}

When the economic values listed in each DER's row are totaled, it provides a benchmark economic analysis for ranking that DER for a particular system goal. The cost-benefit analyses are shown below, and result in the order in which the DER units should be ranked. 
Cost-Benefit Analysis Results:

Unit $A \rightarrow \$ 50-\$ 5-\$ 20+\$ 30=\$ 55$

Unit $\mathrm{B} \rightarrow \$ 30-\$ 8+\$ 30+\$ 40=\$ 92$

Unit $C \rightarrow \$ 40+\$ 0+\$ 12+\$ 50=\$ 102$

This simple process for selecting DER also applies to a DER dispatch algorithm. In this case, dispatch in this order: Units $C \rightarrow B \rightarrow A$. If the system goal is met by dispatching only two DER units, then units $C$ and $\mathrm{B}$ should be dispatched, and unit A should not.

\subsection{Interaction with Multiple Goals}

System Goal 1: Reduce transmission constraint at "Path A" System Goal 2: Reduce emissions

Figure 5 shows the same set of resources being screened for both transmission constraints and emission goals. The proposed process for screening program participants defers the complications encountered in multiple goal analysis (or multiple objective optimization) to DER dispatch. This example begins to reveal the complexity encountered in these situations.

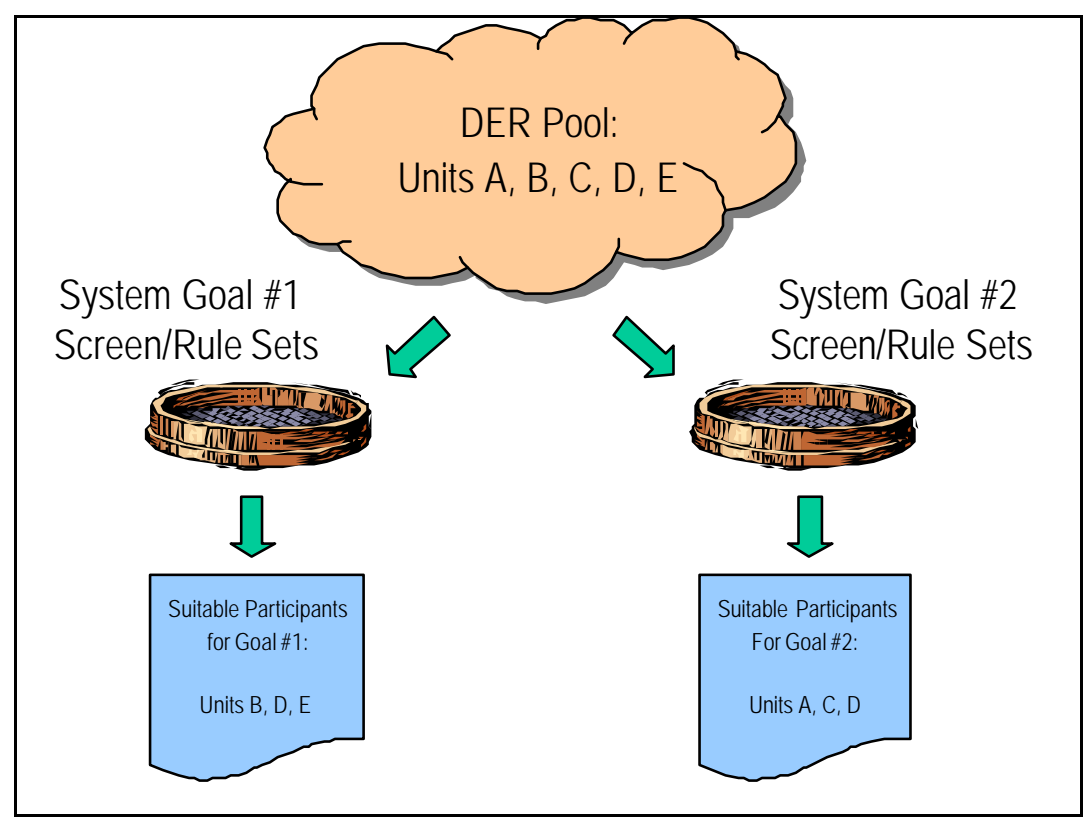

Figure 5. Dispatch Considerations under Multiple Goals 
A similar economic analysis is done for this case as was done in example 1 (see Table 5). However, the difference will exist in the evaluation process.

Table 5: Value of DER Benefits with respect to Two Goals

\begin{tabular}{|l|l|}
\hline Goal 1: Reduce "Path A" Constraint & Goal 2: Reduce Overall Emissions \\
Cost-Benefit Analysis: & $\underline{\text { Cost-Benefit Analysis: }}$ \\
\hline Unit $\mathrm{B} \rightarrow \$ 55$ & Unit $\mathrm{A} \rightarrow \$ 41$ \\
Unit $\mathrm{D} \rightarrow \$ 92$ & Unit $\mathrm{C} \rightarrow \$-22$ \\
Unit $\mathrm{E} \rightarrow \$ 102$ & Unit $\mathrm{D} \rightarrow \$ 82$ \\
\hline
\end{tabular}

But now, conflicting goals must be identified. Table 6 lists every possible combination of DER dispatching. Along the top row are all the possible combinations of system goals that could be addressed, including the "Do Nothing" option. Boxes within the matrix that are grayed out are combinations that are not possible. For example, DER unit A has the ability to reduce emissions, but does not have the ability to reduce "Path A" transmission constraint. Therefore, under DER unit A, the boxes labeled "Goal1" and "Goals 1\&2" are grayed out, indicating that they are not possible solutions. DER unit B has the ability to reduce "Path A" constraints, but cannot reduce emissions, therefore it has grayed out boxes labeled "Goal $2 "$ and "Goals $1 \& 2 "$.

Table 6: Dispatch Decision Matrix

\begin{tabular}{|c|c|c|c|c|}
\hline DER Unit & "Do Nothing" & Goal 1 & Goal 2 & Goals 1\&2 \\
\hline A & $\$ 0$ & & $\$ 41$ & \\
\hline B & $\$ 0$ & $\$ 55$ & & \\
\hline C & $\$ 0$ & & $-\$ 22$ & \\
\hline D & $\$ 0$ & $\$ 92$ & $\$ 82$ & $\$ 174$ \\
\hline E & $\$ 0$ & $\$ 102$ & & \\
\hline
\end{tabular}

After all non-grayed out boxes have been economically evaluated, the DER are ranked by selecting the highest economically attractive option for each DER unit. Therefore, for this example, the order of economic attractiveness is as follows:

Dispatch in this order $\rightarrow$ D, E, B, A (Do not dispatch C), and DER units should be dispatched in this order, until the system goals are met.

This process shows some interesting relationships. As can be seen in Table 6 , the clear winner for Goal \#1 when it is evaluated by itself is DER unit E. However, when Goals 1 and 2 are evaluated in tandem, it becomes clear that the DER unit D is the overall winner. An important point is that it is insufficient to evaluate the dispatch of DER with respect to only one system goal at a time. Each DER unit must consider how it impacts each system goal, regardless of the reason it is being dispatched. 


\subsection{Future Directions}

BPA's EnergyWeb initiative is reaching out to the Pacific Northwest community of distributed energy stakeholders to determine important questions concerning the impact of increased integration of DER in the power system and how EnergyWeb concepts might best be deployed. A series of demonstrations and analyses are being considered for EnergyWeb activities over the next 3 to 5 years. A plan for prioritizing these activities and arranging evaluations of the demonstrations is being prepared. The screening criteria work is expected to contribute to some of these activities and be advanced according to their needs. 


\subsection{References}

Bonneville Power Administration. 1993. "Resource Program Environmental Impact Statement." DOE/BP-2075, Bonneville Power Administration, Portland, Oregon.

EPA. 1998. “Portable Diesel Generator Emissions Regulations: 63 FR 56968.” Environmental Protection Agency, Washington, D.C. October 23, 1998.

EPA. 1999. "Northeast States for Coordinated Air Use Management, Heavy-Duty Diesel Emission Reduction Project RetroEPfit/Rebuild Component." EPA420-R-99-014, Environmental Protection Agency, Washington, D.C.

EPA. 2001. "Non-road Diesel Emission Standards: Staff Technical Paper.” EPA420-R-01-052, Environmental Protection Agency, Washington, D.C.

Goldman, Heffner, and Kintner-Meyer. 2002. “Impact of Enabling Technology on Customer Load Curtailment Performance.” Lawrence Berkeley National Laboratory, Berkeley, California.

Gregerson and Van Holde. 2001. "The Heat is ON: What's Cookin' with Large DG." E-SOURCE, Boulder, Colorado.

Guttromson, R. 2002. "Modeling Distributed Energy Resource Dynamics on the Transmission System.” IEEE Transactions on Power Systems, Vol 17, No. 4, November 2002.

Key, T. 2001. "Distributed Resource Integration Issues." EPRI PEAC contribution for IEEE PES Working Group on Distributed Resources Integration, Presented at IEEE Summer Power Meeting, Vancouver, Canada, July 1002.

Lasseter, R., R. Guttromson, et al 2002. "Integration of Distributed Energy Resources, the MicroGrid Concept.” LBNL-50829, Lawrence Berkeley National Laboratory, Berkeley, California.

Northwest States' and California's Emission Review Processes, Available URL: http://www.energy.state.or.us/siting/sitecom.htm.

Oregon Emissions Plans for DG, Available URL: http://www.deq.state.or.us/aq/generators.htm. 
Appendix A

\section{Practical Considerations for DER Screening}




\section{Appendix A: Practical Considerations for DER Screening}

Celerity Energy, a participant in the EnergyWeb project, has experience in integrating distributed generation into systems. Two areas where they are actively engaged are based in New Mexico and Colorado. Discussions with Celerity Energy revealed practical information that can be helpful to determine prescreen thresholds or rank potential program participants. The straightforward aspects of this information have been incorporated into the main report; however, the responses below provide insight into issues that are typically encountered in the field today.

1. What do you typically see already set up for distributed generation (DG) in the field and what do you need to put in place to either interconnect or separate to meet local load?

RESPONSE--The vast majority of auxiliary generators are not set up for parallel operation with a utility system. Basically they are often sized to only provide the critical customer loads. Usually the customers' non-critical loads are not provided for in emergency plant planning. Some plants may have provisions to separate the critical and non-critical loads, so that the utility could serve the non-critical loads while the generator served the critical loads. However, this is not typically found in existing configurations.

The electrical issues include coordination with utilities regarding interconnection requirements. This can be a time-consuming process caused primarily by a lack of clear procedures internal to the utility. Customer coordination, synchronization, relay protection, disconnecting and isolating switches, revision of control schemes to provide for remote control of the generator, provision of modem interface for internet communication, etc. are all items that need addressing when pursuing a paralleling arrangement.

2. What is the minimum level of pre-existing configuration you require that makes it worthwhile to upgrade? This is mostly a financial question. Perhaps the owner would be interested in co-funding upgrades to participate in a program. Can we formulate some sort of financial threshold for screening in this regard?

RESPONSE--There are several outcomes that can satisfy the objectives of the aggregator, depending on the market conditions that are being met. If load shedding within a predetermined time, say 10 minutes, is desired, the following solutions can work:

a. If load is smaller than the site generation resource and export is not critical -

i. A transfer switch arrangement can be incorporated. The typical approach is for a "hard transfer", where the customer's load is disconnected from the utility grid prior to the generation unit being brought on-line. Without some kind of UPS system in place, the customer will experience a momentary loss of service until the generator can pick up the internal load. The capital costs associated with this may involve environmental permitting, engineering review, some controls upgrades, 
communications and possibly a UPS, depending on the sensitivity of customer load, totaling $\$ 10$ to $\$ 30 / \mathrm{kW}$. This number is low if you include the UPS, which could take the number to at least $\$ 100 / \mathrm{kW}$.

ii. Some utilities permit a "soft transfer", where a generator set can be started while the load is connected to the grid. This condition will exist for about 1 second, then the transfer switch disconnects the load and generator from the grid. This allows a brief period for the generator to pick up the load and minimizes customer service disruption. The capital costs associated with this configuration may involve environmental permitting, engineering, an upgrade in the transfer switch, controls and communications totaling $\$ 20$ to $\$ 50 / \mathrm{kW}$.

b. If load is smaller than the site generation resource and export is desired as a result of a need for capacity and energy for sectionalizing, voltage support and/or VAR support on a feeder -

This is a situation where paralleling and synchronous operation is necessary. Distribution system analysis is an important step to ensure the optimal solution is developed for the utility and customer's needs. There are several software packages that can provide this type of analysis. Switchgear and controls change-outs are necessary, and interconnection coordination with the utility is required. The capital costs associated with this configuration will involve environmental permitting, engineering, paralleling switchgear, engineering, interconnection fees to reimburse the utility for its review and engineering costs (as applicable), electrical installation and materials (conductor, conduit, connections), controls, communications and start-up, totaling $\$ 150$ to $\$ 200 / \mathrm{kW}$.

c. If the site generator is smaller than the load -

iii. Customer cannot shed its loads, cannot pick up all critical loads with the generation and cannot disconnect from the grid. To be useful, the resource must be paralleled or additional on-site generation added. The costs associated with this are outlined above, plus new generation at a cost of $\$ 300$ to $400 / \mathrm{kW}$. The minimum generator size that proves cost effective (assuming site conditions are straightforward) is about $750 \mathrm{~kW}$. The capital costs are as outlined above in $\mathrm{b}$.

iv. Customer's electrical loads can be rerouted to have critical loads picked up by generation with the rest of the loads shed - This involves environmental permitting, engineering, electrical installation and materials, controls and communications, totaling $\$ 20$ to $\$ 40 / \mathrm{kW}$.

v. Customer's electrical loads can be rerouted to have critical loads picked up by generation while the balance of the load is served by the grid - This involves environmental permitting, engineering, electrical installation and materials, controls and communications totaling $\$ 40$ to $\$ 60 / \mathrm{kW}$ (similar capital costs as second bullet above, but fewer $\mathrm{kW}$ removed from the grid). 
3. Is there a rule of thumb on age of installation that you will consider?

RESPONSE--Age is a factor but operating hours and maintenance records are more critical factors. Generally, units older than 20 years relate to higher risk of performance. Units that are not equipped with electronic controls are not suitable for partic ipation and are generally older units.

4. What measurement and control points do you require? Measurements: real and reactive power output, voltage, accumulated energy, switch positions? Control: real power output, voltage, supervisory switching?

RESPONSE--The requirement for information varies depending on the application that is pursued. The need to define the data/information needed by all parties; determine the source of data; how the data is transacted into useable information; and then shared or controlled is also a necessary first step. For those applications where a customer's load can be curtailed and on-site generation serves local load, the generator provides sufficient information to monitor performance remotely. Generator output, hours of operation and alarms for out-of-tolerance operation are important, as is information on fuel supplies so that re-supply can occur in a timely fashion. Utility load data is also important because load that is shed may be larger than the generation capacity. Proper credit for capacity reductions cannot be given without this information.

For parallel operation, close to reattime information reporting on generator operation is important to ensure that contractual obligations for delivery are being met. Measured data either collected and later downloaded or sent via bursts of packet data are important to document performance for capacity payments, for billings and to trigger maintenance tasks. In addition to those noted, time run, fuel gauge reading, non-start or malfunction data transmission, and battery power are items that can be alarmed. 
Appendix B

Survey Questionnaire 


\section{Appendix B: Survey Questionnaire}

\section{Questions by Category}

Responses Choices

\begin{tabular}{|c|c|}
\hline \multicolumn{2}{|l|}{ Organization } \\
\hline What type of organization is responsible for dispatching this generator? & $\begin{array}{l}\text { [municipal, industrial, } \\
\text { commercial, private etc] }\end{array}$ \\
\hline \multicolumn{2}{|l|}{ What is the name of the owning organization? } \\
\hline \multicolumn{2}{|l|}{ What is the mailing address of the owning organization? } \\
\hline Who is the contact for technical questions/c orrespondence? & [name/phone] \\
\hline Who is the contact for contractual /business correspondence? & [name /phone] \\
\hline \multicolumn{2}{|l|}{ Generator Info } \\
\hline What is the generator's primary purpose? & $\begin{array}{l}\text { [primary supply, reliability, } \\
\text { price hedge, speculative } \\
\text { energy] }\end{array}$ \\
\hline What is the generator make and model? & $\begin{array}{l}\text { [reciprocating, diesel, } \\
\text { hydro, microturbine, other] }\end{array}$ \\
\hline Is the generator 3-phase or 1-Phase? & [1] or [3] \\
\hline What is the age of the generator? & [years] \\
\hline What is the type of fuel used? & $\begin{array}{l}\text { [diesel, nat gas, gasoline, } \\
\text { propane, etc] }\end{array}$ \\
\hline \multicolumn{2}{|l|}{ Rating } \\
\hline What is the nameplate rating of the generator & {$[\mathrm{MVA}, \mathrm{PF}, \mathrm{V}]$} \\
\hline $\begin{array}{l}\text { How many hours per year of full-load operation is the nameplate rating valid } \\
\text { for? }\end{array}$ & [hours per year] \\
\hline $\begin{array}{l}\text { Does this generator have a peaking rating that is higher than its nameplate } \\
\text { rating? }\end{array}$ & [y] or $[\mathrm{n}]$ \\
\hline \multicolumn{2}{|l|}{ If yes, what is it and what are its constraints? } \\
\hline \multicolumn{2}{|l|}{ Operating History } \\
\hline What amount of the time is the generator typically operating? & [hours/month] \\
\hline When operating, at what rating is it typically dispatched? & {$[\mathrm{MVA}, \mathrm{PF}]$} \\
\hline
\end{tabular}

B.1 


\begin{tabular}{|c|c|c|}
\hline Questions by Category & Responses & Choices \\
\hline \multicolumn{3}{|l|}{ Availability } \\
\hline How fast can the generator be started and fully loaded from a cold condition? & & [minutes] \\
\hline Are there any restrictions to operations that affect the device's availability? & & $\begin{array}{l}\text { If yes, list restrictions and } \\
\text { any periods of unavailability }\end{array}$ \\
\hline What is the day tank fuel capacity? & & [gallons] \\
\hline If there is an auxilary fuel tank, what is its capacity? & & [gallons] \\
\hline Is the fuel tank shared with other devices (boiler, furnace, etc.) & & [y] or [n] \\
\hline $\begin{array}{l}\text { How many hours of fuel supporting full load operation is stored directly in the } \\
\text { generator fuel tank? }\end{array}$ & & [hours] \\
\hline What is the minimum dispatchable output? & & {$[\mathrm{kW}]$} \\
\hline What is the maximum allowable generator dispatches per month? & & [times per month] \\
\hline $\begin{array}{l}\text { What is the minimum and maximum allowable duration of operation } \\
\text { accumulated over a period of time? }\end{array}$ & & $\begin{array}{l}\text { [min hours per year] and } \\
\text { [max hours per year] }\end{array}$ \\
\hline $\begin{array}{l}\text { What is the minimum and maximum allowable duration of operation when } \\
\text { called upon? }\end{array}$ & & $\begin{array}{l}\text { [min hours per dispatch] } \\
\text { and [max hours per } \\
\text { dispatch] }\end{array}$ \\
\hline Is the generator configured to support blackstart procedures? & & [y] or [n] \\
\hline $\begin{array}{l}\text { Does operation depend on renewable resources being available... solar, wind } \\
\text { etc? }\end{array}$ & & [y] or [n] \\
\hline \multicolumn{3}{|l|}{ If yes, please describe } \\
\hline $\begin{array}{l}\text { Does operation rely on other plant processes (such as shared cooling or lube } \\
\text { oil systems, or fuel pre-processing like bio-mass)? }\end{array}$ & & [y] or [n] \\
\hline \multicolumn{3}{|l|}{ If yes, please describe } \\
\hline \multicolumn{3}{|l|}{ Communications and Control } \\
\hline $\begin{array}{l}\text { Is there presently telephone or internet access at the site of the generator } \\
\text { supporting } 9600 \text { baud rate or above? }\end{array}$ & & [y] or [n] \\
\hline What type of generator controller interface exists? & & $\begin{array}{l}\text { [e.g. LAN running Modbus } \\
\text { or LONWORKS] }\end{array}$ \\
\hline
\end{tabular}

B. 2 


\begin{tabular}{|c|c|c|}
\hline Questions by Category & Responses & Choices \\
\hline Does the generator have an adjustable voltage, VAR or PF controller? & & $\begin{array}{l}\text { List all that apply [VAR, PF, } \\
\text { Voltage] }\end{array}$ \\
\hline Does the generator have the ability to be remotely dispatched from shutdown? & & [y] or [n] \\
\hline Does the generator have analog measurements available for feedback? & & $\begin{array}{l}\text { [list all that apply: P, Q, } \\
\text { Volts, Freq) }\end{array}$ \\
\hline Does the generator have component status's available for feedback? & & $\begin{array}{l}\text { [list all that apply: switch } \\
\text { position, low battery, alarm } \\
\text { conditions etc.) }\end{array}$ \\
\hline \multicolumn{3}{|l|}{ Interconnection } \\
\hline What are the regional interconnection requirements? & & [e.g. IEEE P1547] \\
\hline Is the generation presently synchronizable to the grid? & & [y] or $[\mathrm{n}]$ \\
\hline Does the generator currently have automatic synchronization switchgear? & & [y] or [n] \\
\hline \multicolumn{3}{|l|}{ Location } \\
\hline What is the street address of this generator? & & [address] \\
\hline What is the approximate latitude and longitude of this generator? & & [Lat, Long] \\
\hline How far away from the distribution substation is the generator located? & & $\begin{array}{l}\text { [miles of distribution line } \\
\text { from substation] }\end{array}$ \\
\hline $\begin{array}{l}\text { What is the name and rating of the distribution substation serving the feeder to } \\
\text { which this generation will be attached? }\end{array}$ & & $\begin{array}{l}\text { [e.g. PacifiCorp "Wilbur } \\
\text { Ave." substation, 40MVA, } \\
69: 13.8 \mathrm{kV}\end{array}$ \\
\hline \multicolumn{3}{|l|}{ What is the BPA regional designation for this location? } \\
\hline \multicolumn{3}{|l|}{ Financial } \\
\hline What is the estimated capital to integrate the resource? & & {$[\$]$} \\
\hline What is the minimum price for dispatch? & & {$[\$ / k W h]$} \\
\hline \multicolumn{3}{|l|}{ Miscellaneous } \\
\hline Is there any requirement that the generator be manned during operation? & & {$[\mathrm{y}]$ or $[\mathrm{n}]$} \\
\hline \multicolumn{3}{|l|}{$\begin{array}{l}\text { If yes, what are typical times/days personnel are available to man the } \\
\text { generator? }\end{array}$} \\
\hline Are there an existing operating and environmental permits for the generator? & & [y] or [n] \\
\hline Do emissions restrict the operation of the generator? & & {$[\mathrm{y}]$ or $[\mathrm{n}]$} \\
\hline \multicolumn{3}{|l|}{ If yes, what are the restrictions? } \\
\hline Does the exhaust have adverse impacts? E.g., not vented or noise issues. & & [y] or [n] \\
\hline \multicolumn{3}{|l|}{ If yes, please describe } \\
\hline Do adverse weather conditions affect the operation of the generator? & & [y] or $[\mathrm{n}]$ \\
\hline If yes, please describe & & \\
\hline
\end{tabular}

\section{B. 3}

